\title{
The Role of Industry Studies and Public Policies in
}

\section{Production and Operations Management}

\author{
Nitin R. Joglekar \\ Questrom School of Business \\ Boston University, Boston, Massachusetts 02215, USA \\ joglekar@bu.edu \\ Jane Davies \\ Judge Business School \\ Cambridge University, Cambridge, CB21AG, UK. \\ j.davies@jbs.cam.ac.uk \\ Edward G. Anderson \\ McCombs School of Business \\ University of Texas, Austin, Texas 78712, USA \\ Edward.Anderson@mccombs.utexas.edu
}

\begin{abstract}
The research domain Industry Studies and Public Policy (IS\&PP) seeks to further our understanding of industrial practices and managerial challenges by explicitly considering contextual details in the design and interpretation of research studies. These details can be vital considerations when shaping public policies. This article reviews a sample of IS\&PP publications and analyzes the content of 180 selected papers -85 papers published in the Production and Operations Management (POM) journal and 95 papers published in related journals between 1992 and 2014. Our analysis of the sample dataset and examination of exemplar papers provide four findings. First, studies in different industries emphasize different themes of operational decisions. This difference in emphasis reveals potential research opportunities, especially for conducting inter-industry studies. Second, our analysis reveals a shift in focus over time. Earlier studies contain a mix of benchmarks and inter-industry comparisons, while later studies tend to be context-specific, intra-industry studies. Third, we report on empirics $\rightarrow$ analytics $\rightarrow$ empirics cycles that reveal gaps for building novel theories. Finally, we observe that the relationship between POM decisions and public policy is bidirectional. This highlights the need to jointly examine operational decisions with policy considerations, especially in information goods, healthcare, sustainable operations and high-tech manufacturing industries. Keywords: Context-based Research, Industry Studies, Public Policy, Production \& Operations Management

History: Received: March 2015; Accepted: August 2016 by Kalyan Singhal, after 2 revisions.
\end{abstract}




\section{Introduction}

Industry studies have been defined as "research that demonstrates significant personal investment in developing an understanding of the markets, firms and institutions of an industry and frequently involves the integration of direct observation with appropriate theory and analysis" (ISA 2015). Consistent with this definition, Industry Studies and Public Policy (IS\&PP) researchers take a multi-thematic approach to understanding firm- and industry-level issues (Giarratani et al. 2013, p. 3). The heritage of industry studies can be traced to Adam Smith (1723-1790), who established the scientific foundation of economics and its social effects by grounding his work in the direct observation of production processes. The general approach to industry studies combines qualitative, in-depth case studies with applied quantitative methods to increase the awareness of industry-specific characteristics that influence managerial decision making. In POM, industry studies address managerial activities such as supply chain development, service delivery, and research and development (R\&D) decisions within a single industry, or comparative studies across similar industries, or both. Allied public policy research seeks to understand the courses of action, regulatory measures, laws, and resource allocation as set by a governmental entity or its representatives. POM studies have traditionally involved the linkage between observed industrial practice and the public policies that affect those practices. While some legislation, governmental fiscal support, taxes, and incentive schemes may affect all industries similarly (e.g., minimum wage, unemployment benefits), many policies impact specific industry sectors uniquely. For example, the U.S. Food and Drug Administration (FDA) policies shape the U.S. pharmaceutical industry's dynamics and operating practices (see Anand et al. 2012; Macher and Boerner 2012;).

This paper examines trends in IS\&PP by reviewing the POM literature in this research domain. In keeping with the spirit of leveraging details in IS\&PP, we quantitatively analyze the content and provide a qualitative context through exemplar studies in research design and inference making. The motivation for this research is to establish a roadmap for future POM research on industry and public policy issues. A central tenet of the IS\&PP research approach is that context influences industry dynamics by shaping the decisions of individual actors in general and collective industry actions in particular (Lester 1995). This approach has been deployed in disparate academic disciplines ranging from economic geography (Giarratani et al., 2013) to political economy (Berger 2013). The focus on contextual details creates a natural affinity for POM scholars who observe and theorize about operational decisions of an organization (e.g., a factory, hospital, retail store etc.), a firm, a supply chain or an industry. For instance, the research underlying the book, The Machine That Changed the World (Womack et al. 1990), an exemplar amongst POM studies, was based on the industry studies approach. This book, based on a five-year study, describes competitive actions in the global automotive industry, along with Toyota's extremely successful leap from mass to lean production. It influenced managerial thought, not only in the automotive industry, but in various industries 
such as aerospace (Nightingale and Mize 2002), retail and textile (Abernathy et al. 1999) and healthcare (Thompson et al. 2003). These follow-on studies showed that implementation success for lean production depended upon contextual details, such as the longer lifecycle of aerospace products compared to automotive products. It has resulted in a series of theory-building studies on process design, productivity, and quality in various fields such as organizational science (Adler et al. 1999), POM (Shah and Ward 2003, 2007) and information systems (Roberts et al. 2006; Parker and Van Alstyne 2010; Anderson et al. 2014). Some of these studies engendered debates about alternative operating strategies and competiveness in specific industries such as automotive, chemicals, computers, information storage, machine tools, and semiconductors (Piore and Sabel 1984; Clark et al. 1985; Dertouzos et al. 1990; Benson et al. 1995; Fine 1998; Anderson et al. 2000; Baldwin and Clark 2000; Cachon and Olivares 2010; Berger 2013). Some scholars have called for sector-specific public policies and regulatory support for manufacturing technologies and operations in telecommunication industries based on the need for integrating $R \& D$ decisions, production yields, downtimes, and production organization in the launch of photonics products (Fuchs 2014). The nexus between industry studies and public policy remains a widely scrutinized arena where contextual details are often the fulcrum of debates.

Another motivation for such studies is that many theory-driven explanations for industrial organization decisions espouse generalized outcomes, such as productivity gains through information technology aimed to apply in various contexts. However, observed phenomena (e.g., country or firm level differences in productivity) have not converged as predicted. Giarratani et al. (2013) argue that industry studies provide a lens for examining the differences between various economic theories. Giarratani et al. also argue that the fundamental organizational changes brought about by globalization (e.g., outsourcing and restructuring), translate differentially into representative firms from different industries because each firm is influenced by its unique context. However, even when firm-specific heterogeneity is modelled explicitly, extant models (e.g., fixed-effects regressions) fail to capture the unobserved heterogeneity between industries, firms, and the allied public policies influencing and governing them. Such heterogeneity, which is best examined through context-specific research, underscores the need for detailed examination, particularly in production systems (Lester 1995).

Focus on context-based specificity often compromises generalizability. Given POM focus on studies that use broadly formulated models to establish widely applicable findings, why should studies narrowly focused on a single industry be pursued? We have identified two potential answers. The first is heterogeneity, which suggests that broadly formulated business rules and policies can have differing, and sometimes unexpected, effects (positive or negative) when the policy implementation is compared across specific industrial contexts. For example, Bitran et al. (2008) has shown that, in general, service customers prefer fast service. However, within the auto insurance industry, fast service by insurance adjustors, which 
results in a shorter time spent with clients, correlates paradoxically with both increased cost because adjusters tend to err on the high side during estimation to minimize the potential for back-and-forth negotiation with customers, and decreased customer satisfaction because customers feel that they have not had their claims properly examined (Senge and Sterman 1992). More recently, Jefferson Pilot Financial defined service process metrics and posted these results so that if problems arose with service time, employees could see where and why the performance was suffering (Swank 2003). Other service firms, such as Progressive Insurance, have implemented operational innovations such as "immediate response claim handling" to create differentiation based on customer concerns about response time after filing claims (Hammer 2004). This highlights the importance of the contextual circumstance moderating the general desirability of shorter service times. We have also seen this type of focus in sister domains. For instance, Porter and van der Linde (1995) linked environmental regulations to competitiveness and the promotion of innovation. Follow-on work in the strategic management field examines the systematic differences across industries (McGahan and Porter 1997; McGahan and Victer 2009). Researchers in this domain have highlighted the need to examine strategic issues within a single context - to explore the micro-foundations of an individual firm's strategy (Teece 2007). Such an approach requires novel types of data or analytical methodologies. For example, medical diagnostics data such as functional magnetic resonance imaging (fMRi) of the brain have shed light on specific organizational theories such as attention control and the emergence of routine practices (Laureiro-Martinez et al. 2015).

Public policy scholars (Colander and Kupers 2014) have called for the examination of policy decisions from the bottom up (e.g., based on an examination of implementation challenges) as well as from the traditional top-down (e.g., driven by a macro-economic view of problems) because these decisions constitute a complex evolving system that involve both top-down and bottom-up considerations. Many public policy makers now design policy to account for the heterogeneity within an industry. For example, healthcare industry laws in the U.S. now regulate the number of days a patient can stay in a hospital following childbirth and various other surgeries, and explicit medical insurance policies account for performance heterogeneity by penalizing high rates of readmissions, which impact operational decisions such as hospital-bed scheduling and medical-rounds sequencing (Brown et al. 2014).

This literature review examines a sample of 180 IS\&PP papers selected based on keywords and related content analysis (described later in the paper). The sample includes 85 papers in the POM Journal from its inception in 1992 to 2014, along with 95 papers published on similar POM topics in 13 related journals over a comparable 22-year period. Based on our analysis of the IS\&PP paper sample, we identify the role of industry studies and public policy as it pertains to research trends in the POM field. (In the Reference section, an “*” denotes inclusion in the POM Journal sample of papers, while a "\#” sign denotes the paper is from another POM-focused journal sample of papers). We find that an increasing number of papers 
published over time in the POM Journal are industry studies (from single digits in the 1990s rising to nearly $10 \%$ of all papers published annually in recent years). These papers may not be explicitly labeled "industry studies" or "public policy" research, however, they all draw upon either industry-specific details or related public policy features to form the underlying research framework. In the next section, we describe aggregate statistics based on these sample papers, including their industry sectors and units of analysis. The contribution of this paper lies in identifying trends and potential gaps in IS\&PP research as it applies to the production and operations management field. Specifically, four findings emerge from our analysis and examination of exemplar papers:

(I) The aggregate analysis reveals that studies in different industries emphasize different themes of operational decisions. We made comparisons based on these themes to point to potential gaps and opportunities in the POM literature for IS\&PP research. This difference in emphasis also reveals particular research opportunities, especially for conducting inter-industry studies. For instance, the technology sector papers in our sample emphasize the impact of R\&D and product design on firm performance in terms of unit cost or development productivity. In contrast, the service sector papers in our sample emphasize the impact of customer service quality and delivery on firms' financial performance and market share. Thus, we suggest that service researchers can identify a new class of opportunities by further exploring the role of service design and development, especially in industries where more technology-enabled services are deployed. Likewise, researchers in the technology sector can consider the role of quality and service delivery, particularly with the current servitization trend (Wilkinson et al., 2009).

(II) Our analysis of the sample yields methodological differences and gaps. Early studies (1992-2002) contain a mix of benchmarks and inter-industry comparisons. Later studies (2003-2014) are dominated by intra-industry research. These two groups also differ in terms of measures and methodology employed. The early studies contain relatively more survey-based data and theoretical or review studies, whilst the later studies show an uptick in analytical models and regressions based on objective data. This trend speaks to the potential to use mixed measures and multi-method (e.g., casework followed by regression analysis) approaches, as well as potential methodology and theory gaps. The IS\&PP research approach by definition supports a multi-method orientation to understanding context and policy implications.

(III) We also observe empirics $\rightarrow$ analytics $\rightarrow$ empirics cycles, with successive papers building on findings within a single industry that are derived from distinct methodologies. Recognition of such cycles can also spur new research ideas and directions. Sister disciplines such as industrial organization in economics have also reported a shift from an early emphasis on cross-industry empirical studies, to theory-based research and then a return to single-industry empirical research (Bresnahan and 
Schmalensee 1987). The focus on context-rich industry data offers new and more nuanced theories of operations, and also strengthens the linkages between operations management and sister disciplines like marketing and finance. See, for instance, Gaur and Fisher (2005) and Kesavan et al. (2010) for discussions on measuring retail inventories, follow-on use of inventories, and retail profit data to improve forecasts, or see Van Donselaar, Gaur et al. (2010) for a discussion of the linkages between ordering behavior and automated replacement.

(IV) The relationship between operations management and public policy is bi-directional. Exogenous policies shape operational decisions, yet the implementation challenges associated with operational decisions can in turn create the case for alternative public policies. Importantly, this bi-directionality often hinges on the industry context. For instance, Atasu and Van Wassenhove (2012) point out how producers in the e-waste context adjust for differences in how legislation impacts different supply chain members. Over time, we found an increasing number of publications that study the interface between production and operations management and public policy, especially in sectors such as healthcare and high-tech manufacturing. Based on these studies, we identify opportunities for such further studies in section 4 .

The rest of the article is organized as follows. Section 2 details the selection process and aggregate statistics of our sample of 180 papers. Section 3 describes the theory content and related research design choices within the sample. It also describes some exemplar papers for cross- and single-industry studies (sections 3.1 and 3.2) along with the previously mentioned empirics $\rightarrow$ analytics $\rightarrow$ empirics cycles observed in the sampled papers (section 3.3). Methodological challenges and opportunities are discussed in sections 3.3, 3.4 and 3.5. Section 4 addresses the intersection between industry studies and public policy research, and the dual-causality between them through feedback effects. Section 5 identifies the studies opportunities and limitations. Section 6 summarizes the findings with a forward looking commentary on ways to identify potentially fruitful research directions.

\section{Data Set and Aggregate Findings}

This section describes the sample collection rationale and the study's boundaries. It includes the aggregate statistics for the sample of 180 published papers used in our review. We then conduct a content analysis of these papers to identify key themes and structures used in industry studies and public policy research. We identify and compare frequently occurring themes and related information about business and policy trends across industries to examine patterns and identify areas of strength and gaps in the assembled sample of papers. These patterns allow us to make inferences about the trends in IS\&PP research. 


\subsection{Sample}

The task of identifying a comprehensive sample of IS\&PP papers in the POM Journal required identification of key search terms along with a clear boundary for excluded papers. We aimed to identify papers in the POM field that had either an industry perspective, a policy focus, or both. We took a dual approach: we performed an initial manual search to test the selection of papers, and then an electronic search using journal database search engines. For the initial search, we manually examined the five most recent years of the POM Journal (January 2009-May 2014) and reviewed each issue to identify papers that reflected an impact on public policy (or vice versa) or offered insights that were relevant to specific industry sectors. As for the search boundary, we did not include papers at the macro level (i.e., research that had a regional or country focus) or papers at the micro level (i.e., studies that examined operating policies on the factory floor level). Independently, this manual examination was replicated by searching for industry studies papers in the POM Journal database for the same five-year period. In the electronic search, we searched for articles that referenced "industry", "industries", "public policy" or "public policies" in the title or abstract, as well as the individual names of numerous industries-automotive, electronics, healthcare, pharmaceutical, steel, retail, clothing, computers, etc. We then confirmed that the electronic search terms captured all the papers found manually and then used these terms to scour the remaining issues of the POM Journal (from 1992 to 2008). In doing so, we identified a total of 85 papers published in the POM Journal since its inception that had an industry or public policy element (identified by a “*” in the references). Later we used these search terms to establish a related-journal sample of papers (described in the next section) that addresses production and operations management themes drawn from peer-reviewed literature in alternate business and management journals.

\section{Figure 1. Industry Studies \& Public Policy} (IS\&PP) Papers in POM Journal by Year

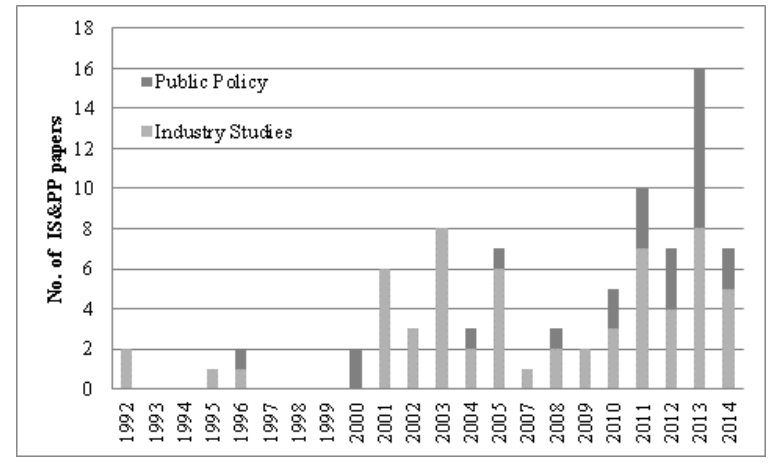

\section{Figure 2. Percentage of IS\&PP Papers in POM Journal by Year}

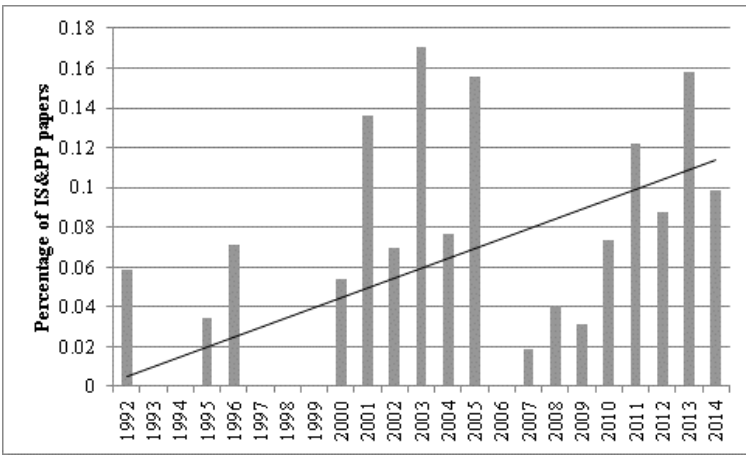

We do not claim that this is an exhaustive list of industry studies and public policy papers in the POM field, but it is representative of the IS\&PP work published between 1992-2014. Across the 22-year history of the POM Journal, we found an increasing number of papers that reflect either an industry or public policy-specific theme (see Figure 1), even when accounting for the general increase in the number of papers 
in each volume over time (see Figure 2). These trends have more than one explanation. First, several of these studies acknowledge their funders, such as government agencies, suggesting that such work is finding increasing support. Second, we also identified several upticks in submissions, as shown in Figures 1 and 2. These spurts generally were associated "special issue" publications with an industry focus, for instance, in areas such as "retail operations" in 2013. The trend line in Figure 2 indicates that our sample includes nearly $10 \%$ of all published papers in the POM Journal in the five most recent years. The POM Journal sample includes 70 industry studies and 15 public policy papers; the trends are pertinent to both types of work.

An examination of the sample papers indicates that research on a wide variety of industries has been published in the POM Journal (see Figure 3). While papers in manufacturing, technology and healthcare dominate, 20 different industry groups based on the nature of the tasks (e.g., type of manufacturing) were identified. The selected papers also reflect the different units of analysis (see Figure 4) with a mix of research at the project, product, process, factory, firm, supply chain and industry levels, demonstrating that IS\&PP research can occur across many units of analysis, not just at the firm or industry level.

Figure 3. IS\&PP Sample Papers in POM Journal by Industry

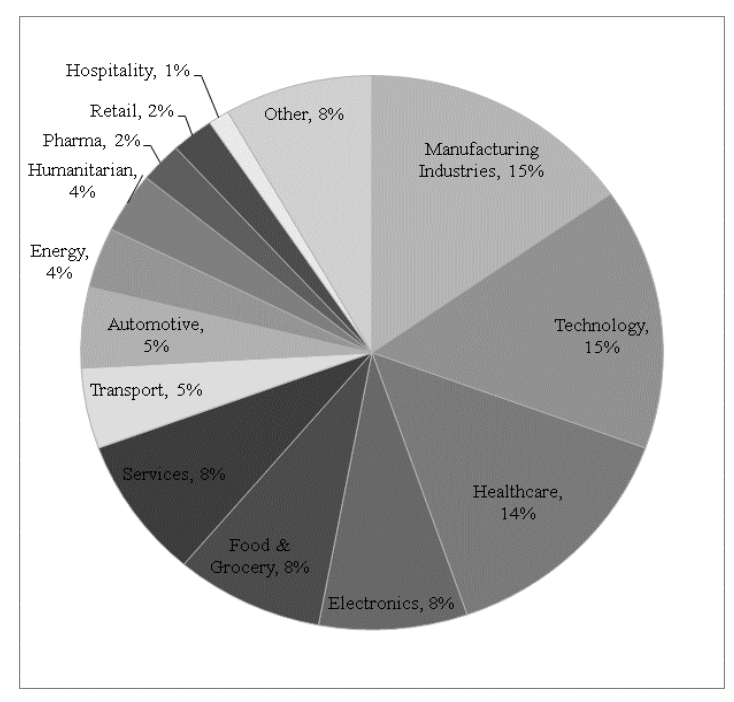

Figure 4. IS\&PP Sample Papers in POM Journal by Unit of Analysis

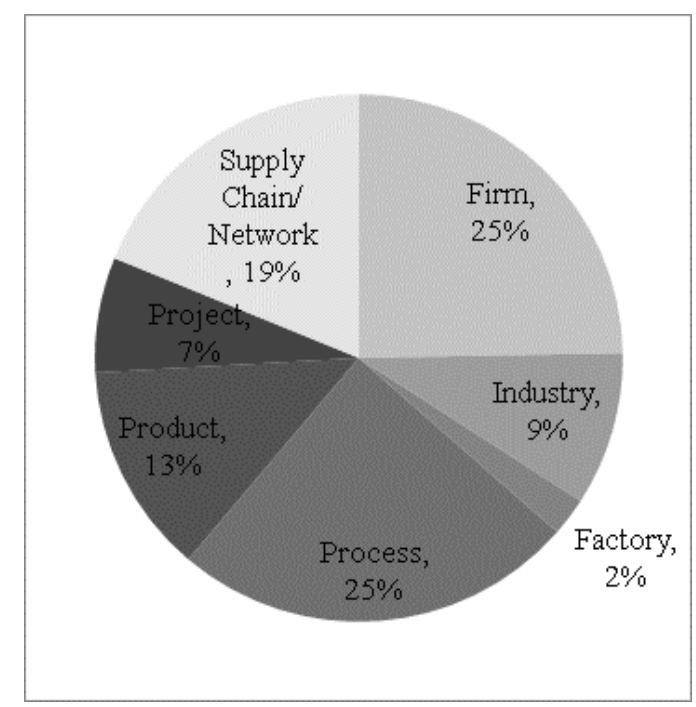

To compare the themes and methodologies of POM Journal sample papers and IS\&PP research published in related peer reviewed journals, we collated a benchmark set of papers with a POM focus that were published in other peer-reviewed management journals. We conducted an electronic search process similar to how we identified key papers in the POM Journal over the same timeframe, but we selected only well-cited papers (based on Google Scholar ordering criteria) with a POM focus. In addition, related papers were identified via recommendations from the POM Journal IS\&PP Department's senior editors. We also included all the Industry Studies Association award-winning papers since the inception of the award in 2009. In total, we assembled 95 related IS\&PP papers dating from 1984 to 2014, a 30-year timespan (these 
papers are identified by a “\#” in the references). These papers came from 13 journals: Organization Science, Management Science, Journal of Operations Management, Manufacturing \& Service Operations Management, International Journal of Automotive Technology and Management, International Journal of Operations \& Production Management, International Journal of Production Economics, IEEE Transactions on Engineering Management, Strategic Management Journal, Journal of Service Management, Journal of Service Research, Managing Service Quality, and Operations Research. The number of IS\&PP papers in these related journals is comparable to the POM sample with 86 industry studies and nine papers specifically addressing public policy.

These related papers also reflect a broad base of industries (see Figure 5), but they are dominated by technology, automotive and manufacturing sectors, with a total of 15 industries represented. The sample also represents a mix of units of analysis (see Figure 6), although with more of an emphasis on firm- and process-level analysis than the POM Journal sample. This was not unexpected given the array of journals represented in the related journal sample.

Figure 5. Related Journal Sample Papers by Industry

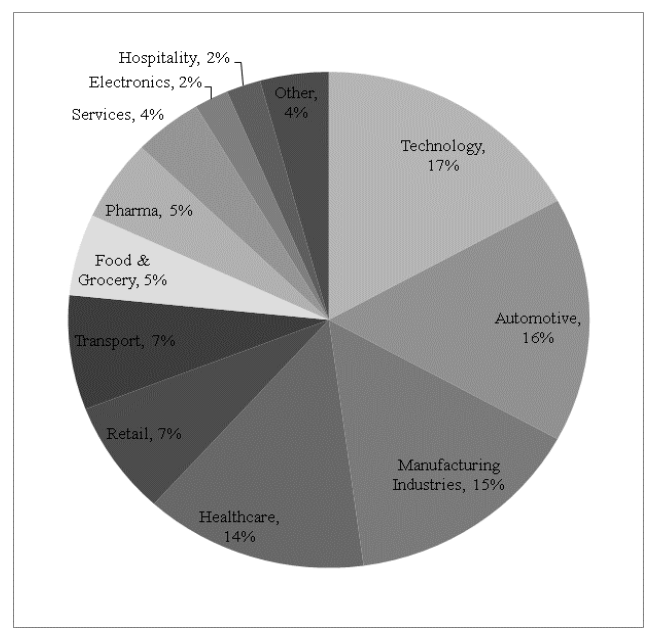

Figure 6. Related Journal Sample Papers by Unit of Analysis

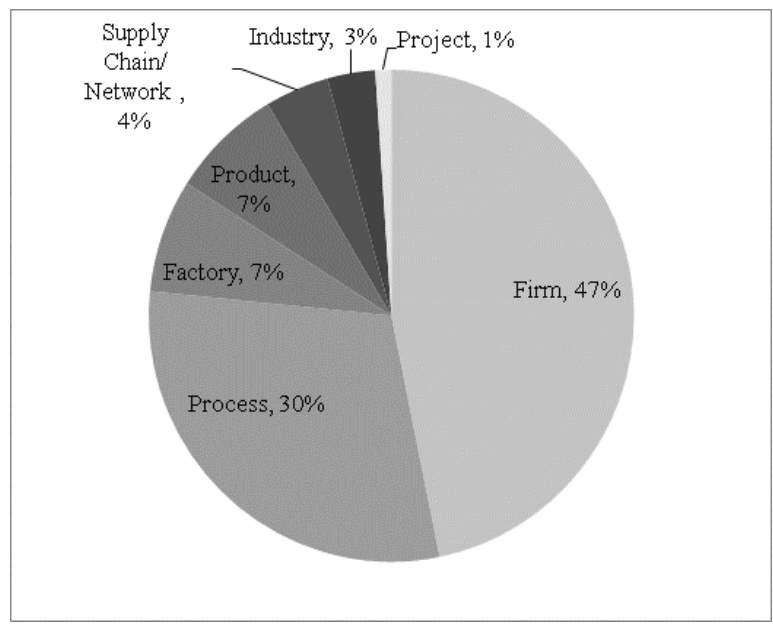

\subsection{Theme Analysis and Gaps in Industry Studies and Public Policy Research}

To examine the themes and structures used in industry studies and public policy research, we entered the combined set of 85 POM Journal and 95 related journal sample papers into a content analysis database (WordStat). Content analysis enables objective and systematic analysis of information (Holsti 1969). Using the content analysis software, we identified over 340 phrases related to POM decisions that appeared in at least $10 \%$ of the combined 180 papers (the full list of phrases is available from the authors on request). These phrases were found by an adaptive-selection algorithm that scanned the entire text corpus and identified phrases describing specific operating decisions. 
These key phrases were then grouped (based on similarity using the content-analysis algorithm cited above) into 45 themed categories (e.g., production, service, cost, flexibility, supply chain, product development). In order to arrive at these themes, phrases were then grouped by an algorithm in the WordStat content-analysis software based on commonality of terms, (e.g., the cost theme includes the key phrases low cost, cost reduction, operational cost, production cost). These themes cover a broad spectrum of topics that address organizational strategies, structure and performance in the operations management field. The top themes, which were represented in over $50 \%$ of the papers, are detailed in Table 1.

Table 1. Top Themes in the combined POM Journal and Related Journal Sample of IS\&PP Papers

\begin{tabular}{c|l|c|} 
& Theme & \% CASES \\
\hline 1 & Cost & $84.3 \%$ \\
\hline 2 & Management & $75.8 \%$ \\
\hline 3 & Product & $72.5 \%$ \\
\hline 4 & Performance & $71.3 \%$ \\
\hline 5 & Operation & $71.3 \%$ \\
\hline 6 & Process & $65.2 \%$ \\
\hline 7 & Time & $62.9 \%$ \\
\hline 8 & Supply Chain & $62.4 \%$ \\
\hline
\end{tabular}

\begin{tabular}{|r|l|c|} 
& Theme & \% CASES \\
\hline 9 & Market & $61.8 \%$ \\
\hline 10 & Flexibility & $56.2 \%$ \\
\hline 11 & Competition & $55.1 \%$ \\
\hline 12 & Quality & $54.5 \%$ \\
\hline 13 & Service & $53.4 \%$ \\
\hline 14 & Workforce & $52.2 \%$ \\
\hline 15 & Innovation & $51.7 \%$ \\
\hline 16 & Risk & $51.1 \%$ \\
\hline
\end{tabular}

We also grouped these data by industry sectors. Identified differences in themes by industry sector highlight how the focus of operational decisions varies across industries. It also identifies potential gaps, and therefore opportunities, to consider for different types of operational choices as an industry evolves. For instance, the contributions from studies on product development practices in the technology sector are shown near the top in Table 2, Column 1. Clark (1989) showed that Toyota enjoyed a clear advantage over its U.S. competitors in terms of person-hours required to deliver a design. However, we have yet to see parallel studies in the service sector industries. We note that our sample includes papers that explore relatively newer phenomena (e.g., off-shoring to supply chain partners followed by in-shoring to local producers, or broad offshoring activities that are delivered in diverse ways but mainly through offshore dedicated centers run by vendors or through fully owned captive centers, (see Bhalla, Sodhi et al. 2008)). Further, we anticipate that novel business models, emergent regulations and technologies (e.g., the use of drones and 3-D printing in supply chains) will prompt scholars to take a fresh look at established findings for specific themes and build on these within focused industry studies.

Next, we explored the differences in the themes identified in the most commonly studied industry sectors: technology, manufacturing, healthcare, automotive and services (see Table 2, $\mathrm{N}$ is the number of papers drawn from respective sectors). The technology sector papers emphasized the research, development and design of products and the associated cost to the firm and performance. In healthcare, the papers accentuated the performance of the delivery system, particularly in terms of cost and quality. The 
manufacturing industry papers considered the production process, both from a structural (e.g., batching) perspective and an infrastructure (e.g., training and flexibility) perspective, along with how the firm performed in terms of market share. For the automotive sector, the production process was a popular theme, along with design and development, quality, volume and lead times. Finally, for the service sector, the emphasis was on the impact of customer service quality and delivery, and firm financial performance and market share.

Table 2. Themes Identified by Top Industry Sectors

\begin{tabular}{|c|c|c|c|c|c|c|c|c|c|}
\hline Technology & $\begin{array}{c}\% \text { of } \\
\text { Papers } \\
(\mathrm{N}=29)\end{array}$ & \begin{tabular}{|l} 
Manufacturing \\
Industries
\end{tabular} & $\begin{array}{c}\% \text { of } \\
\text { Papers } \\
(\mathrm{N}=27) \\
\end{array}$ & Healthcare & \begin{tabular}{|c|}
$\%$ of \\
Papers \\
$(\mathrm{N}=25)$ \\
\end{tabular} & Automotive & \begin{tabular}{|c|}
$\%$ of \\
Papers \\
$(\mathrm{N}=20)$ \\
\end{tabular} & Services & $\begin{array}{c}\% \text { of } \\
\text { Papers } \\
(\mathrm{N}=11) \\
\end{array}$ \\
\hline$R \& D$ & $45 \%$ & $\begin{array}{l}\text { PRODUCTION } \\
\text { PROCESS }\end{array}$ & $49 \%$ & $\begin{array}{l}\text { IMPROVE } \\
\text { PERFORMANCE }\end{array}$ & $57 \%$ & $\begin{array}{l}\text { PRODUCTION } \\
\text { PROCESS } \\
\end{array}$ & $41 \%$ & SERVICE QUALITY & $64 \%$ \\
\hline $\begin{array}{l}\text { COMPETITIVE } \\
\text { ENVIRONMENT }\end{array}$ & $42 \%$ & LOW COST & $45 \%$ & $\begin{array}{l}\text { PERFORMANCE } \\
\text { MEASURE }\end{array}$ & $53 \%$ & PRODUCT QUALITY & $41 \%$ & $\begin{array}{l}\text { CUSTOMER } \\
\text { CONTACT } \\
\end{array}$ & $64 \%$ \\
\hline $\begin{array}{l}\text { PRODUCT } \\
\text { DEVELOPMENT }\end{array}$ & $42 \%$ & BATCH & $45 \%$ & LOW COST & $28 \%$ & $\begin{array}{l}\text { PRODUCTION } \\
\text { VOLUME }\end{array}$ & $41 \%$ & $\begin{array}{l}\text { FINANCIAL } \\
\text { PERFORMANCE }\end{array}$ & $56 \%$ \\
\hline LOW COST & $38 \%$ & TRAINING & $41 \%$ & SERVICE QUALITY & $28 \%$ & LEA.D TIME & $35 \%$ & MARKET SHARE & $56 \%$ \\
\hline PRODUCT DESIGN & $38 \%$ & MARKET SHARE & $34 \%$ & DELIVERY SYSTEM & $28 \%$ & \begin{tabular}{|l} 
PRODUCT \\
DEVELOPMENT
\end{tabular} & $35 \%$ & SERVICE DELIVERY & $56 \%$ \\
\hline $\begin{array}{l}\text { FIRM } \\
\text { PERFORMANCE }\end{array}$ & $35 \%$ & $\begin{array}{l}\text { MANUFACTURE } \\
\text { PROCESS }\end{array}$ & $34 \%$ & $\begin{array}{l}\text { SYSTEM } \\
\text { PERFORMANCE }\end{array}$ & $28 \%$ & PRODUCT DESIGN & $35 \%$ & CUSTOMIZE & $56 \%$ \\
\hline
\end{tabular}

Finally, an alternative method to identify patterns in the sample papers is the type of methodologies (e.g., empirical versus analytical) deployed in these papers over time (see Figure 7).

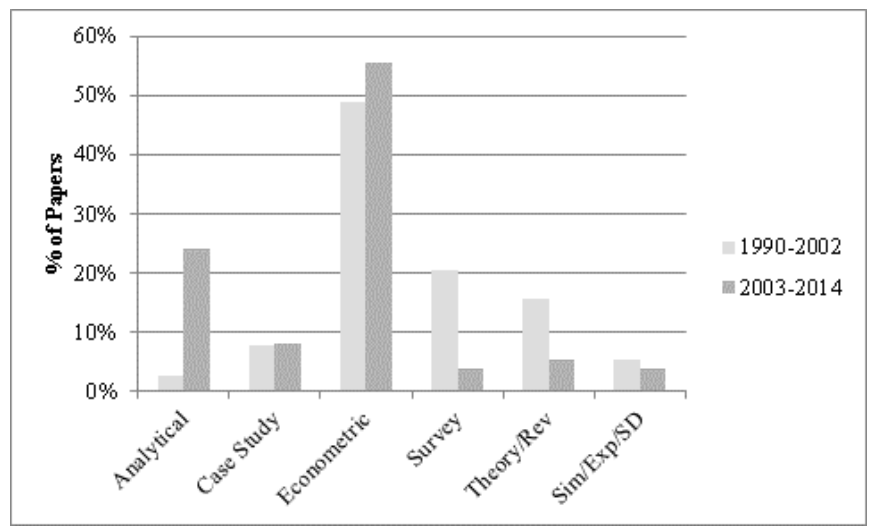

Figure 7. Percentage of IS\&PP Papers from 1990-2002 \& 2003-14 by Method

We split the sample chronologically — the first 12 years of the POM Journal (1990-2002), and the last 12 years (2003-2014). We note that the number of IS\&PP papers in the latter half of the sample, 137, is nearly 3 times larger than the earlier papers, 39, reflecting the increasing number of IS\&PP papers over time, as highlighted earlier. Analytical work garners a much larger relative share in the later half (3\% vs. 
$24 \%$ of the papers), while perceptual or survey data is comparatively larger in the earlier papers (21\% vs. $4 \%$ of the papers). Regression studies dominate both generations - 49\% and 55\% of the papers. These trends are further analyzed in the next section through content analysis.

\section{Industry Studies: Assessment of Content}

One way to further examine this evidence is to consider the research practices within inter-industry studies as compared to practices within a single industry. In our analysis, papers in the earlier period included a sizable number of inter-industry benchmark studies (33\% of the papers) whereas papers in the later period are dominated by single-industry studies ( $94 \%$ of the papers). In this section, we assess the content, in terms of both themes and methodologies in each generation of IS\&PP studies.

\subsection{Inter-Industry Benchmarking}

The research on benchmarking received an initial boost based on Clark et al.'s (1985) productivity and quality trade-off arguments. This work was followed by the seminal "Made in America" study of competitive positioning in key industries in the manufacturing sector (Dertouzos et al. 1990); this study documented performance measures (e.g., quality, innovativeness and time to market) in eight manufacturing sectors: semiconductors, computers, and office equipment; automobiles; steel; consumer electronics; chemicals and pharmaceuticals; textiles; machine tools; and commercial aircraft. These performance measures revealed gaps between best versus average practice. Following this study, and using evidence from European Manufacturing Futures Survey (1990), Ferdows and De Meyer introduced the 'sand cone' model, which developed the concept of cumulative capabilities and postulates a sequence in which operations objectives should be achieved. The sequence begins with quality, followed by delivery, production flexibility and cost. In contrast to the examination of cumulative sequences of activities that add up capabilities, other scholars examined the disaggregation of capabilities. For instance, the first paper published in the inaugural issue of the POM Journal (Ward et al. 1992) examined the consequences of restructuring and trimming global manufacturing firms during the 1980s. The authors identified the patterns of employment by occupation in manufacturing industries utilizing different production technologies and the effect of firm size on nonproduction employment. Neely et al. (1994) were among the initial scholars

to focus on manufacturing performance measurements and hypothesized that managers of small- and medium-sized U.K. manufacturing firms attributed the greatest importance to performance measures (e.g., quality or price) that most closely matched their firm's manufacturing tasks. Similarly, Miller and Roth (1994) examined 164 large American manufacturing business units and proposed a classification for manufacturing firms based on relationships among the firm's competitive capabilities (which described the 
manufacturing task), the business context (the business unit strategy), manufacturing activities (manufacturing strategy choices), and manufacturing performance measures.

An influential benchmarking paper in this category explores the impact of three contextual factors factory size, age and unionization — on implementing 22 manufacturing practices that are key factors for lean manufacturing systems across 20 industries (Shah and Ward 2003). Holweg (2007) provided a historical account of related research projects in the automotive sector that led to the formulation and dissemination of some of the most influential manufacturing practices in several industries. This interindustry benchmarking approach continues to provide a solid assessment of competitiveness in settings such as supplier evaluations (Holweg 2007), high tech manufacturing plants (Rosenzweig and Roth 2004), manufacturing and supply networks (Vereecke, Van Dierdonck et al. 2006; Srai and Gregory 2008), mass customization (Rungtusanatham and Salvador 2008), quality improvements (Choo et al. 2007), services (Menor and Roth 2008), and ERP system implementations (Bendoly et al. 2009). This approach has also been used to assess management quality awards in the European manufacturing sector based on considerations such as strategy setting, alignment, delegation, integration, participation, performance measurement, communication and employee development (Loch et al. 2008). Recent notable applications of inter-industry benchmarking include a study of new venture survival based on observing variations in inventory turnover, gross margin and productivity (Tatikonda et al. 2013), assessment of the impact of container transport on global supply chain performance (Fransoo and Lee 2013) and the impact of logistics performance in terms of time, cost, and variability on global trade (Hausman et al. 2013). Thus, interindustry benchmarking, which had represented a dominant share of the earlier publications, continued throughout the period examined to make important contributions to the theories and debates in POM research. The methodologies and measures for such studies have been reviewed in the literature (Boyer and Verma 2000; Rungtusanatham et al. 2003, 2014; Shah and Ward 2007).

\subsection{Intra-Industry Studies}

An alternative to inter-industry benchmarking studies is the focused and context-based intra-industry study of a single industry. A large degree of variation in operating practices across industries is evident in interindustry studies. This variation created the need for more focused and context-based industry studies. The central goal of context-based studies is to better understand managerial choices by direct observations of either perceptual or objective measures embedded in the business processes of a specific industry. Thus, theory development, research design, data collection, and the resulting inferences are context-specific. For instance, the findings from a specific setting such as automotive distribution may not be generalizable to other industries such as healthcare or medical device distribution without some careful adjustments. On the other hand, the focus on a specific context enables scholars to explore specialized variables and operating 
trade-offs that may not be accessible through inter-industry or broader intra-industry studies. This trade-off between generalizability and specialized understanding of the context does not dilute the rigor or validity of a study, but instead provides nuanced opportunities to conduct analyses and draw inferences. For instance, this approach has yielded a series of industry-focused papers on varied dimensions ranging from the assessment of product development performance (Clark 1989), learning effects in the chemical industry (Lieberman 1989) to human resources and work practices (Pil and Macduffie 1996). The Sloan Foundation's past president, Ralph Gomory, pointed out that industrial firms are "far more complex in their strategies, operations, uses of people, and relations to each other and to their suppliers than business or economic theory describes or than statistical data can capture" (Gomory 1993). Intra-industry research initially gained momentum, in part, due to Sloan Foundation grants to various U.S. universities that supported the creation of centers for industry studies in a wide range of areas such as automotive, food, paper, and semi-conductors. For instance, this support enabled a five-year study on the future of the automobile and resulted in the aforementioned book The Machine that Changed the World (Womack et al. 1990). Richard Lester's (1995) essay in the POM Journal postulated that lean production practices identified by Womack et al. (1990) could spread through the automotive industry and that the competitive implications of such diffusion needed closer examination. Lester (1995) also argued for linking POM research to public policy by moving beyond aggregate statistics to obtain detailed knowledge of comparative performance on the manufacturing and design of specific products and services for particular industries, as well as the supply and demand of specific skill sets. Researchers' impact on lean thinking in the automotive sector has stimulated scholars to replicate the studies in other industries such as aerospace/airlines (Cohn and Barnhart 2003), semiconductors (Benson et al. 1995; Macher 2006), and textiles (Abernathy et al. 1999).

To illustrate this approach, we summarize a select set of studies drawn from our dataset that address different aspects of context-based research in the POM field. These studies are drawn from the airlines/aerospace, automotive, energy, and healthcare sectors. The criteria for selection (Schmalensee 1989; Checkland and Holwell 1998) are (1) type of benchmark (e.g., What is being done? How is it being done? What is the consequence of these decisions?), (2) unit of analysis, (3) choice of dependent, independent and control variables, and (4) methodological choices (e.g., aggregation, spatial, and fixed effects) needed to build a context-specific theory and to draw inferences within the industry context. In each of these studies, the authors draw conclusions that may not be valid outside their study context, but are likely to be generalizable within the specific industry studied.

Airlines Industry Exemplars: Lapré and Scudder (2004) explored the cost-quality performance frontiers and addressed how each firm in their dataset made improvements from one frontier level to another. They modeled quality in terms of customer complaints, and cost in terms of operating expenses 
divided by available fleet utilization. (For a detailed operational analysis of aircraft scheduling and utilization improvement, see Cohn and Barnhart's (2003) analytical industry study findings). Lapré and Scudder (2004) aggregated their data to compare airlines that fly focused, specific routes against those that are geographical generalists. Their data captures $93 \%$ of passenger-miles for all U.S. airlines. They focused on operational measures (e.g., complaints), and their analysis and inferences are airline context-specific. While discussing their findings, they related their results not only to other studies from this industry (e.g., Januszewski 2003) but also to the broader theory of performance frontiers (Schmenner and Swink 1998). However, they claim broader validity with a caveat, suggesting "it should be fruitful to develop further measures for asset frontiers.... and interesting to investigate whether our airline findings generalize to other industries" (p. 133). Such work usually leads to follow-up investigations within the same industry context. For instance, Lapré and Tsikriktsis (2006) explored evidence on differential rates of learning about improving service processes across airlines and then related their findings to Gittell's (2003) observations on the differences in knowledge-sharing practices at American Airlines and Southwest Airlines. Deshpande and Arikan (2012) examined the impact of schedules on flight delays and showed that, along with revenue drivers (e.g., average fare) and competitive measures (e.g., market share), operational characteristics such as the hub-and-spoke network structure also significantly impacted the scheduled on-time arrival probability. More recently, Ramdas et al. (2013) explored whether financial markets can inform operational improvement efforts in the airlines industry. They found that the penalties that carriers face for long delays are significantly higher if carriers operate a high percentage of short-haul or connecting flights or if they incur fewer long delays.

Automotive Industry Exemplars: Our dataset contains a series of studies that explore the operational details unique to the automotive sector (Sako and Helper 1998, Lieberman et al. 1999, Fisher et al. 1999; Novak and Eppinger 2001; Novak and Stern 2008; Ramdas and Randall 2008). We chose two papers as exemplars. The first, Lieberman and Dhawan (2005), identified inter-firm differences in efficiency using the stochastic-frontier production function analysis method. Using data from 11 Japanese and U.S. automobile manufacturers, Lieberman and Dhawan developed measures of resources and capabilities (e.g., work in progress, sales ratio, design quality) and tested for the association of these measures with firm performance (e.g., profit per employee). While this work sheds light on the applicability of the resourcebased theory, the authors are careful to claim that operational effectiveness alone is not sufficient for a firm to achieve a sustainable competitive advantage when operational improvements can be easily imitated. Such findings are not possible by exploring aggregate performance across industries because they must draw on industry-specific details. Lieberman and Dhawan (2005) argued that the differentials they identified in the automotive industry had been sustained for long periods. They assert that, "many years or decades have been required to achieve the imitation of superior scale and organizational skills. Consequently, lagging 
firms have converged only slowly to industry best practice (if at all), while stronger firms like Toyota have made continual advances, thereby maintaining or expanding their lead" (p. 1074).

The second exemplar paper in the automotive industry, Cachon and Olivares (2010), measured the effect of various factors that drive up inventory-holding costs. The relevant outcome was variation in the days of supply held by the dealers by vehicle model type and year at all major U.S. automotive firms. They explained this variation by tracking measures such as demand fragmentation in the distribution channel, number of vehicle models in a segment, sales trends, and plant utilization, while applying both plant- and model-level controls. In doing so, their paper illustrates substantial and persistent levels of differences in finished-goods inventory levels for the U.S. automotive industry.

Healthcare Exemplars: Tucker and Singer (2015) is an exemplar taken from a rapidly growing body of healthcare operations literature. Their paper tested the effectiveness of the practice of "management-bywalking-around" (Peters and Waterman 1982) through a randomized field study that examined the quality of problem solving during improvement projects at U.S. acute care hospitals. The independent variables included such factors as the number of visits by senior managers and number of staff safety forums. The study controlled for the type of site (e.g., either teaching or a general hospital, financially sound or in distress, specialty care provided or none) and the authors found that the management-by-walking-around practice, on average, negatively impacted worker's perception of performance. To explain this surprising finding, the authors used mixed methods to examine the impact of the work area's problem-solving approach. Results suggested that prioritizing easy-to-solve problems was associated with improved perception of performance. In terms of public policy, the authors argued for a design of financial incentive mechanisms to encourage the adoption of appropriate, rather than easy-to-solve, problems in these programs. For instance, policy makers could provide incentives for building problem-solving capabilities that improve patient-centered performance rather than advocate for a specific improvement program. This arena is seeing a rapid growth in research publications that either extend or test conventional operations management theories in the health care context such as focused clinical trials (Huckman and Zinner 2008), impact of workload on service time and patient safety (KC and Terwiesch 2009) and the tension between safe and patient-centered health care based on process management choices (Chandrasekaran, Senot and Boyer 2012).

Retail Exemplars: Scholarly research on retail operations has grown into a specialized field. The POM Journal published a special issue (Fisher 2013) on retail operations and created an editorial department to promote this body of research. This research seems to center on industry specific constructs. Fisher, while providing a historical perspective, points out that "retailing was on the cusp of transformational change driven by information technology improvements that were making more and better data available with which to understand customers and predict what they would buy. We proposed this idea to a number of 
retailers, and in 1997, 32 of them agreed to work with us on a project, funded by the Sloan Foundation, to understand how information technology would change the way retailers forecast demand and manage supply" (op. cit. p.755). Follow-on studies have revealed three major opportunities: linkage between operational measures and financial performance (Gaur Fisher and Raman 2005), the ability to conduct in store experiments (Gaur and Fisher 2005), and the need to address SKU-level data inaccuracies (DeHoratius and Raman 2008). For brevity, we refer readers to the special issue to examine emergent trends.

Valuation Analysis Exemplars: Hendricks and Singhal's (1997, 2005) research on the association between operational decisions and the valuation of firms has garnered much attention amongst researchers and practitioners. These papers draw upon cross-industry datasets. We identify two exemplars of singleindustry studies that explore such association. The first paper, Thirumalai and Sinha (2011) examined the antecedents for product recalls for medical device manufacturing firms. This industry involves complex supply chains with stakeholders (e.g., device manufacturers, healthcare providers, patients, the FDA and insurers) that work on differing objectives and play different types of roles. Product recalls in this setting are hypothesized to be influenced by prior experience in launching products and by their allied product scope in terms of features; the impact of recall is studied in terms of abnormal returns in the capital market. Thirumalai and Sinha controlled for firm-specific choices such as R\&D expenses and the size of the labor force. This paper also investigated the role of the FDA and public perceptions on observed industry dynamics. The second paper in this domain, Davies and Joglekar (2013) assessed how the valuation of a focal firm is affected by the valuation of its supply chain partners. To measure the supply chain's valuation, the study identified the linkages for all solar energy supply chains and their exchanges (in terms of materials and components supplied). The authors then used operational flexibility measures such as modularity, level of customization, and supply chain integration to examine valuation variation while controlling for industry-specific variables, such as crude oil prices.

\subsection{Case Work, Datatypes and Empirics-Analytical Cycles}

The IS\&PP approach has informed on the heterogeneity in the development of performance measurement practices across multiple industries (Neely et al. 1994). And, consistent with the definition of industry studies, Helper makes an argument for beginning a study by understanding a problem through case work (Helper 2000). Indeed, the trade-off associated with "industry-focused sample and context-specific results" versus "broad industry samples and generalizable results" can be used to inform inductive and deductive reasoning through a careful use of a mixed methodologies (Edmonson and McManus 2007). Some scholars may set upon such work, for example, to examine what a firm's boundary is while thinking about an operating decision. These operating decisions might involve considerations about supply chains and about 
the firm or industry boundary. Could this firm define its distribution network for a single product market or from multiple product markets?

This type of network-centric argument for observing operations and collecting rich data may depend on the way the research question is framed. We draw upon a stylized example of a food safety study put forth by Klochikhin and Lane (2015) to illustrate this point. Klochikhin and Lane argue that a researcher may obtain different flavors of data based on (i) selection of search strategy, (ii) selection of labels and (iii) text processing schemes. For instance, food safety data can be sorted by considerations such as food safety OR food security or by food safety AND food security. Similarly, the labels may consider food safety along with food pathogens (e.g., acanthamoeba OR actinobacteri), biochemistry and toxicology, food processing and preservation, food quality and quality control, and food-related diseases explicitly. Labeling could be broader, for example, National Science Foundation labels this work under categories "life sciences" and "social sciences related to food safety". The use of the text-processing feature such as "based on frequency" could introduce additional labels. Such approaches yield rather large data sets, which could feature outliers, enable fine-grained analysis, incorporate different cost structures, and introduce novel units of analyses base on the choice of labels.

Nearly $30 \%$ of the POM Journal papers and $10 \%$ of the related journal sample articles either feature formal analysis or optimization decisions. Many of these analytical papers also incorporate context-specific data. That is, model formulations enhance or complement the empirical studies by drawing upon contextspecific observations to establish model assumptions, and parameterize the analyses to interpret the results. For instance, Cohn and Barnhart (2003) offer a scheduling framework to inform the number of contextspecific options (e.g., incorporating maintenance routing with crew scheduling by airline planners). It is noteworthy that subsequent empirical work (e.g., Lapré and Scudder 2004, discussed in the previous section) quantified the economic gains associated with such scheduling practices and their impact on industry dynamics. Such accumulation of knowledge across successive publications goes beyond the airlines industry. Other examples for such cycles in our sampled papers involves decisions such as knowhow management in pharmaceutical R\&D (Girotra et al. 2007; Zhang et al. 2011; Macher and Boerner 2012) and examinations of outsourcing and work practices in the automotive industry (Clark 1989; Pil and Macduffie 1996; Novak and Eppinger 2001; Ramdas and Randall 2008).

Interactions between these approaches can in effect create cycles of empirical $\rightarrow$ analytical $\rightarrow$ empirical research (Fisher 2007). For instance, some of the early research on contract manufacturing in the electronics industry using the case method approach offers evidence that original equipment manufacturers (OEMs) sometimes focused on short-term cost improvements at the expense of longer-term capabilities when making outsourcing decisions (Parker and Anderson 2002; Anderson et al 2007). Anderson and Parker 
(2002) formalized this by building a formal learning-by-doing model to explore the applicability of their theory to other industries. Gray et al. (2009) subsequently built a game theory model to illustrate that "without any learning-by-doing," the OEM pursues a static outsourcing strategy. That is, the outsourcing (make-buy) choice does not change from one period to the next. In contrast, learning-by-doing can lead to dynamic outsourcing in which the make-buy choice changes from one period to the next because the OEM and contract manufacturer's production costs are based on past production levels. These observations also stimulated analytical work on contract structure design (Xu et al. 2010) as well as product development in the presence of information platforms with cross-externalities such as videogames (Anderson et al. 2014). These analytical insights partially inspired related empirical work on how learning-by-doing influences quality performance of contract manufacturers vis-à-vis internal plants (Gray et al. 2014) and also on how contractual incentives and monitoring mechanisms relate to the contract manufacturer's perception of the buyer's focus on quality (Handley and Gray 2013). Handley and Gray's (2013) results suggest that buyers can reduce their attention, in terms of outsourcing oversight, to contract manufacturers that face extensive regulatory scrutiny. The original case study (Parker and Anderson 2002) also attracted many enquiries and resulted in a special issue of the POM Journal on Integrating Information and Knowledge Work in Outsourced, Offshored, and Other Distributed Business Networks (Anderson and Parker 2013a). A majority of the papers in this issue are industry studies, with nearly 60/40 split between analytical and empirical work.

Integrative methodologies show much promise within the empiric-analytics cycles. For instance, we see a trend in the growth of structural estimation models that combine a formal model with a dataset from specific industries such as automotive distribution (Cachon and Olivares 2010) and healthcare operations (KC and Terwiesch 2011). Another integrative approach begins with detailed case studies that lead into the development of regression models though an iterative cycle (Edmondson and McManus 2007; Cui, Loch et al. 2012; Tucker and Singer 2015). Sometimes the problem setup requires stepping beyond such iterations by building a feedback loop into the model's structures. System dynamics (Sterman 2000) can relax the constraints created by the need for open-loop formulations and thus capture many of the context specificities of industries often omitted from more formal analysis, leading to context-specific recommendations for particular industries (Senge and Suzuki 1994; Lane et al. 2000; Akkermans and Vos 2003; Anderson and Parker 2013b). Further, system dynamics modeling can often be combined with longitudinal data and hybrid mathematical analysis and structural modeling (Anderson et al. 2000; Oliva and Sterman 2001) to draw insights associated with feedback effects. Such approaches are discussed in the next section. 


\subsection{Methods to Deepen Understanding of Context-Specific Decisions}

A common feature among industry studies is the authors' careful consideration and selection of variables for investigation. In other words, a central theme across these studies is that insights would not be obtained without deeply exploring the context in order to choose industry-specific decision variables. A related trend is the use of panel data (Hausman and Taylor 1981; Hsiao 2014, see Gaur et al. 2005 as an exemplar for POM applications) that enables better control of unobserved firm-specific and time-specific factors while addressing trade-offs between operations variables. In this regard, we highlight three factors that empirical industry studies must carefully consider: disaggregation, fixed effects, and instrumental variables.

Of the 110 empirical studies in our sample, 30 used disaggregation methods to provide context-specific industry insights. An early example of this approach is Lieberman's (1984) paper, which disaggregates the learning curve into component parts by examining individual products relative to plant investment and overall industry capacity in the chemical industry. This study shows that variation in the learning rates can be explained by R\&D investment and capital intensity. More recent papers provide more nuanced insights. For instance, Lieberman and Dhawan (2005) assign economic value to specific variables (e.g., capital invested per worker, vehicles produced per plant) for Toyota and its key competitors, while explaining why Toyota enjoyed a substantial advantage in labor productivity and exploring why it takes years to imitate its superior organizational skills. Cachon and Olivares (2010) examined factors influencing inventory buildup within the automotive industry by disaggregating inventory to the dealership level. Davies and Joglekar (2013) aggregated firm effects to examine the value associated with supply chain choices regarding modularity and integration in the solar energy sector. A commonality among these papers is the consideration of interactions between decisions at the factory or firm level. The advantage of focusing on a single industry is the ability to disaggregate to a level of detail that reflects decision choices specific to that industry. A related methodological opportunity is sometimes available to account for the biases created by selection of disaggregated variables. For instance, in studying inventory levels, Olivares and Cachon (2009) examine the influence of competing retailers at General Motor's dealerships in isolated U.S. markets. They admit to the possibility of an endogeneity bias in the competition measures by pointing out that retailers may choose to enter certain markets based on local market characteristics such as relevant inventory costs. Hence, they develop a two-stage method, with the first stage estimating the endogeneity effect and the second stage, a regression analysis accounted for endogeneity (i.e., number of retailers in a geographically isolated sub-market) while estimating the inventory levels. It is worth noting that these approaches can address a normative, descriptive or prescriptive focus (or any combination thereof). For example, the Olivares and Cachon (2009) paper on automobile dealerships combined a normative and descriptive focus as it first presents the theory on how firms should establish inventory levels based on the 
competition in a market and then follows with a descriptive approach to show how firms actually behave in actual practice. In contrast, Li et al. (2014) combine a descriptive with a prescriptive approach. They first provide a descriptive approach to study how consumer demand behaves in the airline industry and show the degree of inter-temporal substitution on behalf of customers. Then, they prescribe better pricing policies that account for this demand behavior.

Fixed effects also play an important role in the interpretation of inferences in context specific studies. Three-quarters of the empirical industry studies in our sample control for firm-specific fixed factors. In addition to the traditional controls for time, geography, ownership, number of employees, patents and age, the empirical industry studies also reflect more nuanced controls such as oil price in the transportation and energy sectors (Davies and Joglekar 2013); scheduled shifts in production or planned maintenance in the automotive sector (Cachon and Olivares 2010); hospital, patient and procedural characteristics in healthcare studies (Olivares et al. 2008; KC and Terwiesch 2011; Chandrasekaran et al. 2012); and controlling for retailers' product categories or perishable inventory in the grocery sector (Heim and Sinha 2001; Li et al. 2012). An exemplar in our sample of combining disaggregation with fixed effects is the estimation of the individual learning curves for six separate airlines through interaction effects (Lapré and Tsikriktsis 2006). The authors use these estimations to explain Southwest Airline's successful expansion into U.S. East Coast cities.

Finally, 22 papers in our combined sample used instrumental variables, not only to counter issues of endogeneity, but to provide particular insights buried within the context of their industry, and to uncover latent factors often hidden in the 'black box' of secondary data studies. For instance, in the fast food industry, to examine the impact of waiting time on firm performance, Allon at al. (2011) used the 'distance between outlets' to find that competitive dynamics rendered short wait times imperative for success. KC and Terwiesch (2011) use an instrumental variable (distance of patient from hospital) to disentangle the effects on hospital outcomes of improved service delivery versus bias in selecting 'easy-to-treat' patients. In the air travel industry, Li et al. (2014) use instrumental variables to capture an unbiased measure of price sensitivity, a key factor if customers are strategic in their purchases across different air travel markets.

\subsection{Generalizations vs. Specificity: Validity}

The focus on a deeper understanding of contextual decisions raises questions about the choice of constructs, but also about a study's internal and external validity. Inter-industry studies have yielded many examples of careful development of scales (Roth et al. 2008). Some of these scales may not be applicable at a specific level of data collection within a single-industry or they may have to be modified based on the context. Design of single-industry studies face a trade-off between generalization and specificity; however, even so, standards of validity in social science require both internal consistency and generalizability, even in 
industry-specific studies. To reconcile this conflict, reviewers of such studies consider generalizability differently from inter-industry studies. For instance, the selected flexibility measure (or an allied function specification in an analytical model) in a surgical unit in a specific hospital may not be relevant to all other hospitals. More broadly, this trade-off applies to the process of advancing and testing theories about operating practices. Schmenner and Swink (1998) posited a theory of Performance Frontier that has engendered context-specific industry studies (e.g., Lapré and Scudder 2004) and inter-industry studies (e.g., Rosenzweig and Easton 2010). Lapré and Scudder's findings, which generated follow-on scrutiny in peer reviewed publications based on evidence within the airlines industry (e.g., Tsikriktsis 2007), advanced the performance frontiers theory in a manner (based on variable trade-offs associated with routing choices, crew utilization and learning, and public policies in the aftermath of 9/11) that is fundamentally different from Rozenzweig and Easton's approach that takes a broader view of operating strategy consistent with inter-industry formulations (Hayes and Pisano 1996; Roth 1996; Boyer and Lewis 2002; Stratman 2007; Schoenherr et al. 2012). We point to this while noting that both context-based and inter-industry studies now have widespread followings and are making substantive contributions as evidenced in terms of their citation counts.

These observations about research design and generalizations are not limited to theory-driven studies. In the introductory section we pointed to the development of lean operating principles based on descriptive studies within a single firm (Toyota) and comparisons with similar firms (e.g., GM and NUMMI). Subsequent studies contributed to our understating of lean practices both through inter-industry studies (Shah and Ward 2003) and in specific industries (Shah et al. 2008). Similarly, the questions about generalizability are not limited to empirical studies. We have seen several papers in this review wherein an analytical model is developed based on a stylized example. While the model may be valid based on these stylized assumptions, their applicability to the specific industry requires a scale-up that can yield counterbalancing effects that are not evident in the stylized model (for an example of a focused, yet complete model, see Oliva and Sterman 2001).

\section{Operating Decisions and Public Policy}

Industry studies have been used to inform public policy both in a proactive (or longer term anticipatory) and short response time questions (Helper 2015). Examples for proactive analysis include exploring issues such as how policy makers understand and plan for impact of other countries' anticipated investments in industries like nanotechnology, or assessing the critical role of supply chains. An example of short response

time questions is: What barriers block the adoption of lightweight materials across an auto supply chain? Thus, operating decisions can be quite central to public policy making. Literature on the nexus between 
operating decisions within an industry and allied public policies presents the evidence on context-specific decisions in three forms: (1) when public policies shape operating choices, (2) when observed operating practices influence the formulation of policy, and (3) the role of intermediation and intermediaries such as trade associations or standards setting bodies (e.g., the International Organization for Standardization, ISO.org). In this section, policies discussed may pertain to a range of public actions from a specific legislature (e.g., e-Waste regulations in the European Union based on the Waste Electrical and Electronic Equipment (WEEE) directive, which took effect in 2003, see Atasu et al. 2016) or through procedures defined by governmental agencies such as the U.S. FDA (Macher and Boerner 2012). Policies may also be established and implemented based on public programs such as Auctions For Meals, geared to feed school children in Chile (Olivares et al. 2012) and through the creation of agencies such as Advanced Research Projects Agency-Energy (arpa-e.energy.gov) to fund and foster innovation (Erzurumlu et al. 2014).

\subsection{How Do Public Policies Shape Context-Specific Operational Choices?}

To illustrate how public policies influence operating decisions, we draw upon a public policy implementation framework posited by Atasu and Van Wassenhove (2012) as shown in Figure 8. Policy makers recognize that legal "gray zones" exist where the law is ambiguous or silent in some instances, prompting some courts to take no action on "violations" (Landsbergen and Orosz 1996). Based on observations of the rollout of e-waste legislation in Europe, Atasu and Van Wassenhove (2012) posited that such a gray zone exists at the interface of sustainable operations and public policy. They point out three necessary steps to realize necessary to realize its potential economic impact. The first is "the choice of an e-waste policy instrument as discussed in the economics literature, which contain important micro level (operational) decisions. The second phase is the implementation of these policy instruments, while the third phase is the producer response to policy and implementation choices, which can accentuate or attenuate the economic implications of such legislation" (p. 408). 
Figure 8. Atasu and Van Wassenhove's "Gray Zone"

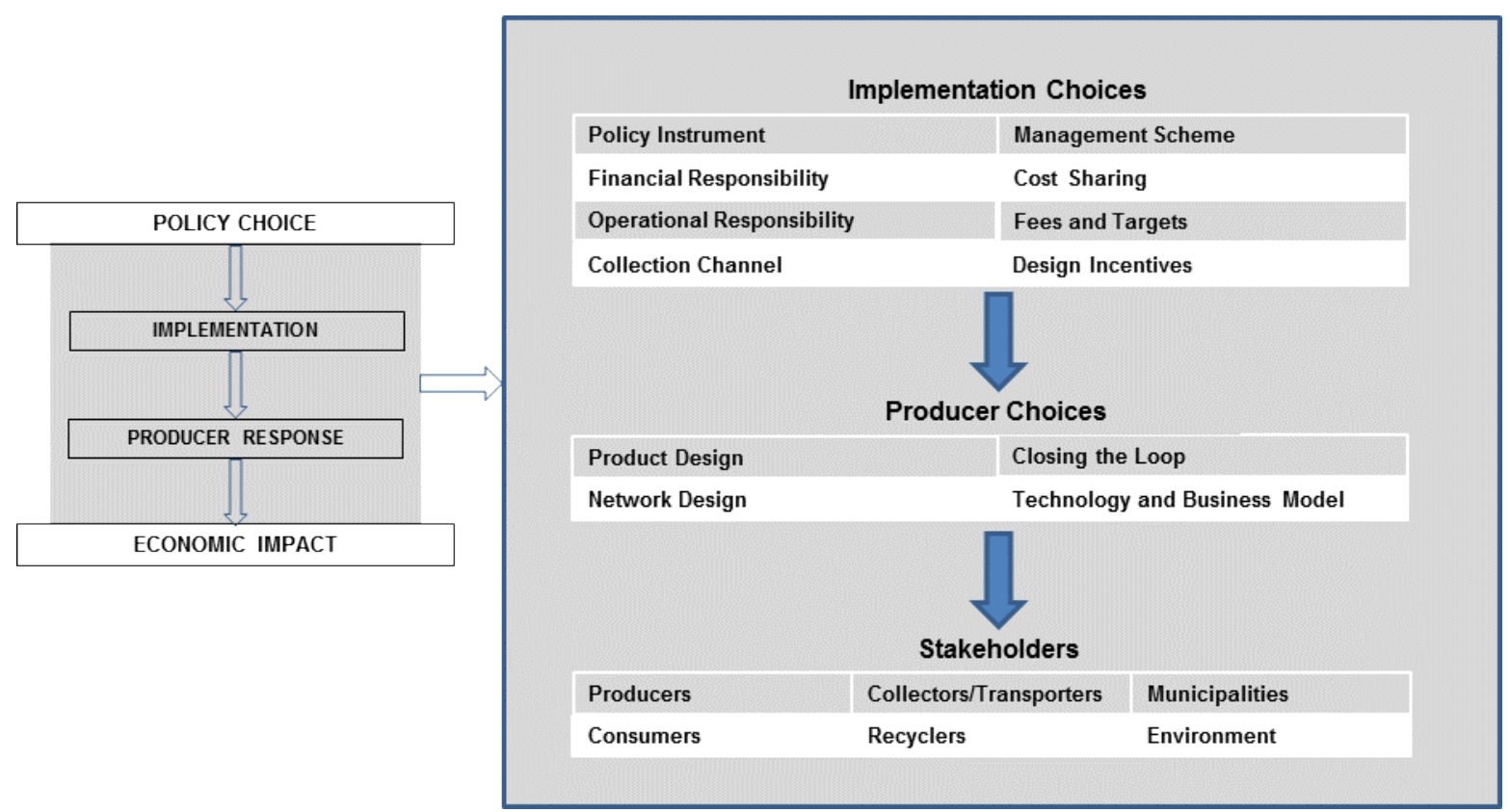

In the e-Waste context, Atasu and Van Wassenhove (2012) point out that producers recognize the variation in how the legislation was implemented by different constituent supply chain stakeholders. For instance, waste collection stakeholders (either municipalities or producers with their own collection system) could allow for single or multiple collection systems. And, independent of the manner in which the waste was collected, either the end users or the producers could bear the costs. Given this heterogeneity, it is possible to build formal models of producer choices and their economic consequences. For instance, Atasu and Subramanian (2012) studied the impact of individual producer responsibility versus collective producer responsibility (IPR vs. CPR), in the context of product take-back laws for e-waste on manufacturers' design for (product) recovery (DfR) choices and profits, and the impact on consumer surplus in the presence of product competition. They found that IPR offers superior DfR incentives as compared to CPR, and provides a level, competitive playing field. They also found that CPR may distort competition and allow "free-riders" on DfR efforts that would reduce product recovery costs.

Thus, manufacturer preferences for IPR or CPR may differ because of the free-riding implications under CPR, even when high-end manufacturers have incentives to free-ride under certain competitive conditions. Thus, from an economic welfare perspective, the policy choice between IPR and CPR is not clear-cut. This choice requires a comparison between the effects of superior recovery cost-reduction through improved DfR under IPR and operational cost-efficiency under CPR. This illustrates the importance of context-specific insights when studying the impact of exogenous policies on operating practices. 
The effect of regulation on operational practices is not limited to "sustainability" legislation. A recent study of combinatorial auctions (CA) in Chilean schools (Olivares et al. 2012) examines how the government procures $\$ 500,000$ of meals each year for school children. They found two key choices in the operating design of CAs: (1) Which meal services should be offered for public bidding? and (2) How diverse should the supplier base be so as to promote competition? The authors use bidding data to uncover important aspects of the bidding firms' cost structure and strategic behavior, both of which the auctioneer cannot directly observe. Their results indicate that package bidding that allows firms to express their cost synergies based on economies of scale and density meet the objectives of CA. However, they also found evidence that firms can take advantage of this flexibility by discounting package bids for strategic reasons and not based on cost synergies. Note again the importance of setting up a theory model and then specifying a context-specific structure to establish the analysis.

However, while public policies can drive lower-level operating design, operational implementation can affect the policy maker's decisions. For instance, Olivares et al. (2012) also suggest that imposing market share restrictions and running sequential auctions seems to promote competition in the long run, without significantly increasing the short-run government costs due to unrealized cost synergies. The concept of operational choices driving public policy is examined next.

\subsection{How Do Operating Decisions, and Individual and Firm Preferences Shape Public Policies?}

Macher et al. (2011) drew upon a unique database of roughly 6,000 international firms to investigate firms' abilities to influence the formulation of governmental policies. They found that country level institutional characteristics, such as the legal order and political diversity of the firm's home country, significantly affect the firm's ability to influence government policy. The results vary significantly by industry (e.g., manufacturing, construction, agriculture) sectors. They also found that industry level characteristics, such as the number of competitors, and firm-level characteristics, such as size and age, are determinants of the firm's influence on governments. The scholarly debates for assessing the cost-benefits of public policy get sharper when the evidence focuses on firm choices within a specific industry segment. We highlight two areas that have garnered considerable attention: healthcare and manufacturing of high-technology devices.

Some healthcare regulations (e.g., the U.S. Affordable Care Act, see Kocher and Adashi 2011) call for incentive payments based on benchmarking performance improvements of. These regulations have specific stipulations in terms of sharing savings (quality and cost) with Medicare and coordinating care across healthcare supply networks. Many of the key performance measures are observed at the operating unit, rather than in aggregate. It is not surprising that a growing number of papers have examined specific healthcare outcomes. For instance, KC and Terwiesch (2009) examined patient transportation services and cardio-thoracic surgery to show that the processing speed of service workers is influenced by their 
workload. These authors raise questions about the current structure in which hospitals receive payment, regardless of the realized cost of care. In exploring improvements in healthcare practices, Tucker and Singer (2015) argued that policy makers can play an important role in improving safety in hospitals by encouraging organizations to build problem-solving capacity (see the discussion of "management by walking around" or MWBA in Section 3). They indicate that, "rather than requiring hospitals to participate in a specific change program, such as MBWA, that may not be fully validated, policy makers could instead provide incentives for hospitals to build the generic capacity to solve frontline problems" (p. 15).

Development of manufacturing technologies, particularly when they interface with R\&D and affect competitiveness of emergent value chains, is another closely examined research area. For instance, Fuchs and Kirchain (2010) compared high-end communications component production and show that technological (e.g., minimum efficient factory size), market (e.g., size and competitors), and institutional (e.g., private equity-backed firms, also see Lerner 2011) factors all affect competitiveness. Drawing upon such evidence, Fuchs (2014) argued for a technologically nuanced policy structure, wherein "it will be critical to avoid a 'one-size-fits-all' policy approach, across technologies and across nations, because policies that enhance one sector can undermine another" (p. 520). Similarly, Gray et al. (2014) found that collocating $R \& D$ and manufacturing positively influenced manufacturing conformance and quality performance, especially for plants with high levels of tacit process knowledge from large firms. Notably, this effect was found to be consistent before and after the broad diffusion of information and communication technologies.

Lenway and Rehbein (1991) found that industries with a large number of firms are likely to choose a leader or a follower strategy rather than a free-rider strategy. Ostrom (2000), while exploring collective actions, noted that studies with a larger number of study participants result in trumping the majority interest. Recently, intermediation through the use of standards has received much interest in this context. Such intermediation may come about through the use of industry groups such as SEMATECH (Grindley et al. 1994) or it may come from individual players aiming to create and control platforms (Parker and Van Alstyne 2010). In our literature review, we found specific papers that examine the roles of quality standards (e.g., ISO9000) in diffusing such interests (Corbett and Kirsch 2001). The use of intermediaries and the creation of standards can have a significant impact on industry structure and competitiveness (Macher et al. 2002).

\subsection{Feedback Effects}

Much like the metaphorical "chicken and egg" question, operations and public policy decisions exhibit dual causality, as shown in the causal-loop diagram in Figure 9. On the right, we see that public policy drives a firm's (and even an industry's) competitiveness. This takes time, however, as shown in the 
"delay" between the two variables. The firm's competitiveness (or lack thereof) leads to operations strategy decisions that influence investments with respect to operational decisions. These decisions ultimately impact public policy directly, and also impact productivity, which policy makers consider when making public policy. However, one could just as easily draw the loop beginning with operational decisions and still complete the loop. A second loop (again with delays) also connects the operations decisions through the variables of public policy, competitiveness, operational risk, behavioral bias, operational decisions, productivity, and, cycling around again, public policy. Finally, it should be noted that competitiveness and operational decisions mutually influence each other, increasing the dynamic complexity associated with the linkages between operations and policy.

\section{Figure 9. Potential for Dual Causality between Operations and Public Policy Decisions}

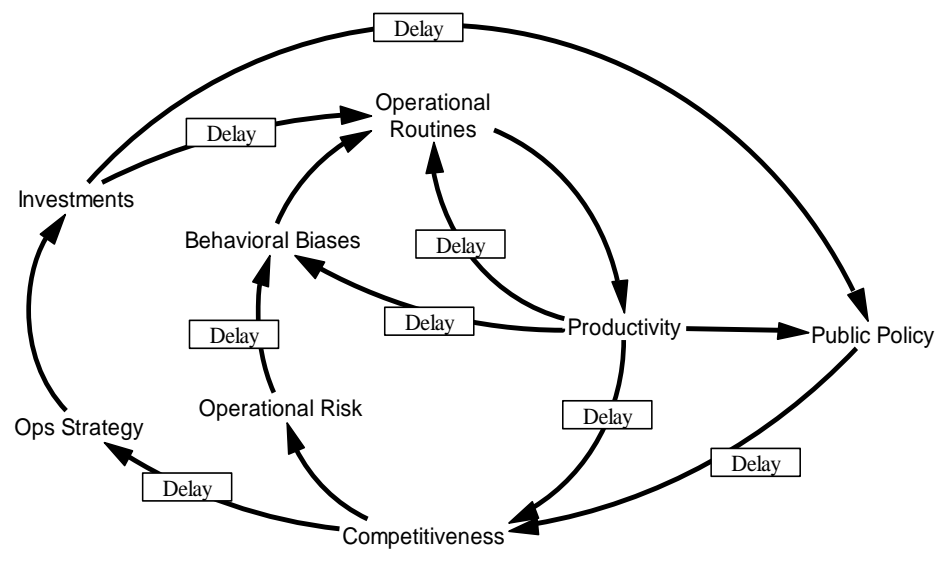

Examples of these mutually interacting dynamics are two potentially ratcheting mechanisms at play in Figure 9. For example, in the 1970s, government-mandated clean air and fuel emissions standards for the automotive industry hurt the North American automotive industry's competitiveness because it had been producing larger cars with accordingly higher emissions and lower fuel economy compared to its Japanese competitors. The U.S. government waited for American auto firms to adapt before issuing further, stricter standards. Similarly, the U.S. government created a different set of standards for light trucks, because domestic manufacturers gained a disproportionate share of this market (Anderson and Joglekar 2012). Another important issue is the handling of lags in the system (shown as "delays" in Figure 9). Not only do the delays differ in length, but these differences must be accounted for both in regression (Sims, 1972) and analytic modeling studies (Anderson and Morrice, 2006). Moreover, in combination with the mutual interactions therein, they complicate the interactions between operations and policy and can render it chaotic (Bar-Yam, 1997). 


\section{Opportunities and Limitations}

We have identified some major gaps in terms of themes (described in Table 1) in the 180 papers that we examined. We sampled a large body of papers from representative publications and identified relevant themes in the field of POM (Kulkarni et al. 2014). Admittedly, the sample and thus the findings will change in the future if the basic IS\&PP themes change. Given this caveat, we have examined public policy implementation challenges in some sectors (e.g., closed-loop supply chains for e-Waste). However, in our dataset of 180 published papers, we did not find comparable sets of papers in settings such as healthcare, food delivery, and humanitarian aid. Similarly, we did not find papers that explore either the consequences of novel business models (e.g., crowd funding of $R \& D$ ) or the unintended consequences of new technologies such as the unmanned aerial vehicle (also called UAV's or drones), radio frequency identification (RFID), or 3-D printing in supply chains. Based on the nexus between operating decisions and public policy described in Sections 4.1 and 4.2, we expected to see common factors, such as the number of industry competitors, and firm level characteristics, such as size and age, as determinants of these decisions. Yet many of the sample studies overlook such considerations. A second issue in this regard is the Lucas Critique (Lucas 1976), "given that the structure of an econometric model consists of optimal decision rules of economic agents, and that optimal decision rules vary systematically with changes in the structure of series relevant to the decision maker, it follows that any change in policy will systematically alter the structure of econometric models" (p. 279). While the original critique appeared in the literature in the macro-economic context, it has drawn the attention of scholars who explore micro-economic issues (McFadden 1986; Chintagunta et al. 2006). This critique has immediate implications for models that sit at the intersection of operations and public policy. Structural estimation methods could be employed to address this criticism (Reiss and Wolak 2007). Several studies in our dataset did not take that route, and many failed to look at counterfactuals. Thus, their findings cannot be applied to scenarios without data. This gap seems to be filling up rapidly in newer studies (see for instance Kim et al. 2014).

This article reviews the state of such research based on content analysis of a set of 180 papers. There are limitations to this sort of framing of a review article. For instance, it does not adequately address some recent trends in the POM field such as the growing emphasis on analytics and data (see e.g., DeHoratius and Raman 2008). It also does not adequately investigate issues such as controlled experiments (Katok et al. 2012) or observations in specific geographic regions (Sodhi and Tang 2013) or decisions made by emergent firms during their startup efforts (Lévesque et al. 2012). However, a series of special issues and journal departments have been devoted to such themes at POM and other journals. We refer readers to the publications in these sister departments, or commissioned special issues, for an overview of these emergent research trends. Arguably, the inclusion of such papers would have increased the number of sample papers in this review. 
A second limitation is that some of the more comprehensive research in industry studies has either appeared in books (e.g., an analysis of information and communications technology ecosystems by Fransman, 2010). Since these books are not amenable to content search, we have included relevant articles from domain journals such as International Journal of Automotive Technology and Management. We have also e excluded some specialized areas such as Energy Policy (e.g., Katzenstein and Apt 2012), that would have required a fuller review in our examination. Other type of research is emergent and is yet to result in peer reviewed publications. For instance, an indicator for the interest in theory building and descriptive industry studies in POM is the response to the POMS Applied Research Challenge that was launched at POMS's 2013 annual meeting. Finalists featured themes such as software process management in federally funded IS projects in the U.S., a data-driven launch and scale-up of retailer Warby Parker, and a detailed examination of lean diffusion practices in Volvo's plants worldwide.

\section{Conclusions}

In summary, our review finds a clear trend towards an increasing emphasis on context-specific research (e.g., case studies, analytical models and data-driven analysis) with specific observations from multiple industries (e.g., airline, automotive, healthcare, and retail supply chains), and research designs at the intersection of industry studies and public policies, especially in advanced manufacturing, healthcare and sustainable operations. Furthermore, several findings emerge from this analysis. One is that different themes predominate in different industry settings, leaving numerous research gaps that we have identified. Another is that, even as the total number of industry and public policy studies published annually has increased over the past decade, there has been a corresponding decrease in inter-industry studies, which we hope will be reversed. Further, this trend is accompanied by novel opportunities for methodological innovation to draw inferences from case studies, and for empirical analysis using primary and now secondary data. There are spill-over effects with research topics crossing over from one industry to another as well as across units of analyses, and there are bi-directional implications for public policy. We also observed empirics-analytic cycles in which a context-rich empirical study of an industry setting provides the basis for follow-on analytical studies. These studies, in turn, often raise new questions that must be studied empirically, prompting the cycle to repeat in a beneficial fashion. Finally, industry studies provide a uniquely valuable platform for studying the implications of and potential prescriptions for public policy initiatives. In essence, we believe that context-specific and evidence-driven scholarship resulting from industry studies has yielded innovative theories and models for 'best in class performance' in the field of POM and will continue to do so as the field grows and matures. 


\section{Acknowledgement}

We thank that the senior editors of the industry studies and public policy department for providing input while initiating the review. We also thank Atalay Atasu, Amy Cohn, Nicole DeHoratius, Charles Fine, John Gray, David Lane, Marvin Lieberman, Jeffrey Macher, Jeffrey Miller, Sriram Narayanan, Marcelo Olivares, Geoffrey Parker, Frits Pil, Stephen Rosenthal, Eve Rosenzweig, Kingshuk Sinha, ManMohan Sodhi, Anita Tucker, Rohit Verma and Peter Ward for their suggestions on the selection of review articles and/or feedback on earlier versions of this manuscript. The paper has also benefitted from feedback based on presentations at Texas Christian University, ISA and POMS annual conferences.

\section{References}

Abernathy, F. H., J. T. Dunlop, J. H. Hammond, D. Weil. 1999. A Stitch in Time: Lean Retailing and the Transformation of Manufacturing--Lessons from the Apparel and Textile Industries, Oxford University Press New York.

\# Abhishek, V., K. Hosanagar. 2013. Optimal Bidding in Multi-Item Multi-slot Sponsored Search Auctions. Operations Research 61(4) 855-873.

Adler, P. S., B. Goldoftas, D. I. Levine. 1999. Flexibility Versus Efficiency? A Case Study of Model Changeovers in the Toyota Production System. Organization Science 10(1) 43-68.

*Aflaki, S., P.R. Kleindorfer, V.S. de Miera Polvorinos. 2013. Finding and Implementing Energy Efficiency Projects in Industrial Facilities. Production and Operations Management 22(3) 503-517. *

\#AhmadBeygi, S., A. Cohn, M. Lapp. 2010. Decreasing Airline Delay Propagation by Re-Allocating Scheduled Slack. IIE Transactions 42(7) 478-489.

*Akkermans, H., B. Vos. 2003. Amplification in Service Supply Chains: An Exploratory Case Study from the Telecom Industry. Production and Operations Management 12(2) 204-223.

*Akyol, D.E., R.B.M. De Koster. 2013. Non-Dominated Time-Window Policies in City Distribution. Production and Operations Management 22(3) 739-751.

*Alanis, R., A. Ingolfsson, B. Kolfal. 2013. A Markov Chain Model for an Ems System with Repositioning. Production and Operations Management 22(1) 216-231.

\#Allon, G., A. Federgruen, M. Pierson. 2011. How Much Is a Reduction of Your Customers' Wait Worth? An Empirical Study of the Fast-Food Drive-Thru Industry Based on Structural Estimation Methods. Manufacturing \& Service Operations Management 13(4) 489-507.

\#Anand, G., J. Gray, E. Siemsen. 2012. Decay, Shock, and Renewal: Operational Routines and Process Entropy in the Pharmaceutical Industry. Organization Science 23(6) 1700-1716.

Anderson, E. G., G. G. Parker. 2002. The Effect of Learning on the Make/Buy Decision. Production and Operations Management 11(3) 313-339.

\#Anderson, E., A. Davis-Blake, S. Erzurumlu, N. Joglekar, G. Parker. 2007. The effects of outsourcing, offshoring, and distributed product development organization on coordinating the NPD process. S. 
Kavadias, C. Loch, eds. Handbook of New Product Development. Elsevier/Butterworth-Heinemann, Burlington, MA, 259-289.

*Anderson, E.G. C.H. Fine, G.G. Parker. 2000. Upstream Volatility in the Supply Chain: The Machine Tool Industry as a Case Study. Production and Operations Management 9(3): 239-261.

Anderson, E.G. N.R. Joglekar. 2012. The Innovation Butterfly: Managing Emergent Opportunities and Risks during Distributed Innovation. Springer, New York.

Anderson, E.G. D.J. Morrice. 2006. Stochastic Optimal Control of Centralized Staffing and Backlog Policies in a Two-Stage Customized Service Supply Chain. Production and Operations Management 15 (2) 263-278.

Anderson, E.G. G.G. Parker. 2013a. Integration of Global Knowledge Networks. Production and Operations Management 22(6) 1446-1463.

*Anderson, E.G. G.G. Parker. 2013b. Integration and Cospecialization of Emerging Complementary Technologies by Startups. Production and Operations Management 22(6) 1356-1373.

Anderson, E.G. G.G. Parker, B. Tan. 2014. Platform Feature Investment in the Presence of $3^{\text {rd }}-$ Party Developer and Consumer Externalities. Information Systems Research, 25(1) 152-172.

*Atasu, A., L.N. Van Wassenhove. 2012. An Operations Perspective on Product Take-Back Legislation for E-Waste: Theory, Practice, and Research Needs. Production and Operations Management 21(3) 407-422.

*Atasu, A., Ö. Özdemir, L.N. Van Wassenhove. 2013. Stakeholder Perspectives on E-Waste Take-Back Legislation. Production and Operations Management 22(2) 382-396.

*Atasu, A., R. Subramanian. 2012. Extended Producer Responsibility for E-Waste: Individual or Collective Producer Responsibility? Production and Operations Management 21(6) 1042-1059.

Atasu, A., Van Wassenhove, L. N., \& Webber, D. (2016). Owls, Sheep and Dodos: Coping with Environmental Legislation. In Environmentally Responsible Supply Chains (pp. 179-197). Springer International Publishing, Cham, Switzerland, 179-197.

*Athanassopoulos, A.D., A. Iliakopoulos. 2003. Modeling Customer Satisfaction in Telecommunications: Assessing the Effects of Multiple Transaction Points on the Perceived Overall Performance of the Provider. Production and Operations Management 12(2) 224-245.

*Azoury, K.S., J. Miyaoka. 2013. Managing Production and Distribution for Supply Chains in the Processed Food Industry. Production and Operations Management 22(5) 1250-1268.

*Baker, E., S. Solak. 2014. Management of Energy Technology for Sustainability: How to Fund Energy Technology Research and Development. Production and Operations Management 23(3) 348-365.

*Baker, T.K., D.A. Collier. 2003. The Benefits of Optimizing Prices to Manage Demand in Hotel Revenue Management Systems. Production and Operations Management 12(4) 502-518.

Baldwin, C. Y., K. B. Clark. 2000. Design Rules: The Power of Modularity, MIT Press, Cambridge.

Bar-Yam, Y. 1997. Dynamics of Complex Systems (Vol. 213). Addison-Wesley, Reading, MA.

\#Bayus, B.L. 1998. An Analysis of Product Lifetimes in a Technologically Dynamic Industry. Management Science 44(6) 763-775. 
*Beckman, S., K.K. Sinha. 2005. Conducting Academic Research with an Industry Focus: Production and Operations Management in the High Tech Industry. Production and Operations Management 14(2) 115124.

\#Bell, D., S. Gallino, A. Moreno. 2013. Inventory Showrooms and Customer Migration in Omni-Channel Retail: The Effect of Product Information. Working Paper. University of Pennsylvania, Philadelphia, Pa.

Bendoly, E., E. D. Rosenzweig, J. K. Stratman. 2009. The Efficient Use of Enterprise Information for Strategic Advantage: A Data Envelopment Analysis. Journal of Operations Management 27(4) 310-323.

\#Benner, M.J., M. Tripsas. 2012. The Influence of Prior Industry Affiliation on Framing in Nascent Industries: The Evolution of Digital Cameras. Strategic Management Journal 33(3) 277-302.

\#Bennett, V.M. 2013. Organization and Bargaining: Sales Process Choice at Auto Dealerships. Management Science 59(9) 2003-2018.

Benson, R., S. Cunningham, R. Leachman. 1995. Benchmarking Manufacturing Performance in the Semiconductor Industry. Production and Operations Management 4(3) 201-216.

Berger, S. 2013. Making in America: From Innovation to Market. MIT Press, Cambridge.

\#Berry, W.L., M.C. Cooper. 1999. Manufacturing Flexibility: Methods for Measuring the Impact of Product Variety on Performance in Process Industries. Journal of Operations Management 17(2) 163-178.

\#Bhalla, A., M.S. Sodhi, B.-G. Son. 2008. Is More IT Offshoring Better? An Exploratory Study of Western Companies Offshoring to South East Asia. Journal of Operations Management 26(2) 322-335.

Bitran, G. R., J.-C. Ferrer, P. Rocha E Oliveira. 2008. OM Forum-Managing Customer Experiences: Perspectives on the Temporal Aspects of Service Encounters. Manufacturing \& Service Operations Management 10(1) 61-83.

*Blackburn, J., G. Scudder. 2009. Supply Chain Strategies for Perishable Products: The Case of Fresh Produce. Production and Operations Management 18(2) 129-137.

Boyer, K. K., M. W. Lewis. 2002. Competitive Priorities: Investigating the Need for Trade-Offs in Operations Strategy. Production and Operations Management 11(1) 9-20.

\#Boyer, K.K., G.T.M. Hult. 2005. Extending the Supply Chain: Integrating Operations and Marketing in the Online Grocery Industry. Journal of Operations Management 23(6) 642-661.

*Boyer, K.K., R. Verma. 2000. Multiple Raters in Survey-Based Operations Management Research: A Review and Tutorial. Production and Operations Management 9(2) 128-140.

*Bozarth, C., J. Blackhurst, R.B. Handfield. 2007. Following the Thread: Industry Cluster Theory, the New England Cotton Textiles Industry, and Implications for Future Supply Chain Research. Production and Operations Management 16(1) 154-157.

*Brabazon, P.G., B. MacCarthy, A. Woodcock, R.W. Hawkins. 2010. Mass Customization in the Automotive Industry: Comparing Interdealer Trading and Reconfiguration Flexibilities in Order Fulfillment. Production and Operations Management 19(5) 489-502.

Bresnahan, T.F., R. Schmalensee.1987. The empirical renaissance in industrial economics: an overview. The Journal of Industrial Economics 35(4) 371-378.

\#Brown, K.A., P.G. Willis, G.E. Prussia. 2000. Predicting Safe Employee Behavior in the Steel Industry: Development and Test of a Sociotechnical Model. Journal of Operations Management 18(4) 445-465. 
Brown, J.R., J.C. Sox, D.C. Goodman. 2014. Financial Incentives to Improve Quality: Skating to the Puck or Avoiding the Penalty Box. J. Amer. Med. Assn. 311(1) 1009-1010.

\#Cachon, G., S. Gallino, M. Olivares. 2012. Severe Weather and Automobile Assembly Productivity. Working Paper. Columbia Business School Research Paper 12/37, New York.

\#Cachon, G.P., M. Olivares. 2010. Drivers of Finished-Goods Inventory in the U.S. Automobile Industry. Management Science 56(1) 202-216.

\#Campbell, B.A. 2013. Earnings Effects of Entrepreneurial Experience: Evidence from the Semiconductor Industry. Management Science 59(2) 286-304.

*Caro, F., R. Andalaft, X. Silva, A. Weintraub, P. Sapunar, M. Cabello. 2003. Evaluating the Economic Cost of Environmental Measures in Plantation Harvesting through the Use of Mathematical Models. Production and Operations Management 12(3) 290-306.

*Carrillo, J.E. 2005. Industry Clockspeed and the Pace of New Product Development. Production and Operations Management 14(2) 125-141.

*Cayirli, T., E. Veral. 2003. Outpatient Scheduling in Health Care: A Review of Literature. Production and Operations Management 12(4) 519-549.

\#Chandrasekaran, A., C. Senot, K.K. Boyer. 2012. Process Management Impact on Clinical and Experiential Quality: Managing Tensions between Safe and Patient-Centered Healthcare. Manufacturing \& Service Operations Management 14(4) 548-566.

Checkland, P., S. Holwell. 1998. Action Research: Its Nature and Validity. Systemic Practice and Action Research 11(1) 9-21.

Chintagunta, P., T. Erdem, P. E. Rossi, M. Wedel 2006. Structural Modeling in Marketing: Review and Assessment. Marketing science 25(6) 604-616.

\#Choi, T.Y., K. Eboch. 1998. The TQM Paradox: Relations among TQM Practices, Plant Performance, and Customer Satisfaction. Journal of Operations Management 17(1) 59-75.

Choo, A. S., K. W. Linderman, R. G. Schroeder. 2007. Method and Context Perspectives on Learning and Knowledge Creation in Quality Management. Journal of Operations Management 25(4) 918-931.

*Christensen, C.M. 1992. Exploring the Limits of the Technology S-Curve. Part I: Component Technologies. Production and Operations Management 1(4) 334-357.

\#Christensen, C.M., F.F. Suárez, J.M. Utterback. 1998. Strategies for Survival in Fast-Changing Industries. Management Science 44(12) 207-220.

\#Clark, J.R., R.S. Huckman. 2012. Broadening Focus: Spillovers, Complementarities, and Specialization in the Hospital Industry. Management Science 58(4) 708-722.

Clark, K. B. 1989. Project Scope and Project Performance: The Effect of Parts Strategy and Supplier Involvement on Product Development. Management Science 35(10) 1247-1263.

Clark, K. B., R. H. Hayes and C. Lorenz. 1985. The Uneasy Alliance: Managing the ProductivityTechnology Dilemma. Harvard Business School Press, Boston, Mass.

\#Cohn, A.M., C. Barnhart. 2003. Improving Crew Scheduling by Incorporating Key Maintenance Routing Decisions. Operations Research 51(3) 387-396. 
Colander, D., R. Kupers. 2014. Complexity and the Art of Social Policy: Solving Society's Problems from the Bottom Up, Princeton University Press, Princeton, NJ.

\#Conlon, E., S. Devaraj, K.F. Matta. 2001. The Relationship between Initial Quality Perceptions and Maintenance Behavior: The Case of the Automotive Industry. Management Science 47(9) 1191-1202.

*Corbett, C.J., D.A. Kirsch. 2001. International Diffusion of ISO 14000 Certification. Production and Operations Management 10(3): 327-342.

*Crandall, R.E., R.E. Markland. 1996. Demand Management-Today's Challenge for Service Industries. Production and Operations Management 5(2) 106-120.

*Cui, Z., C. Loch, B. Grossmann, R. He. 2012. How Provider Selection and Management Contribute to Successful Innovation Outsourcing: An Empirical Study at Siemens. Production and Operations Management 21(1) 29-48.

*Davies, J., N. Joglekar. 2013. Supply Chain Integration, Product Modularity, and Market Valuation: Evidence from the Solar Energy Industry. Production and Operations Management 22(6) 1494-1508.

\#de Figueiredo, J.M., B.S. Silverman. 2007. Churn, Baby, Churn: Strategic Dynamics among Dominant and Fringe Firms in a Segmented Industry. Management Science 53(4) 632-650.

\#de Figueiredo, J.M., B.S. Silverman. 2012. Firm Survival and Industry Evolution in Vertically Related Populations. Management Science 58(9) 1632-1650.

\#DeHoratius, N., A. Raman. 2008. Inventory Record Inaccuracy: An Empirical Analysis. Management Science 54(4) 627-641.

\#Dennis, D., J. Meredith. 2000. An Empirical Analysis of Process Industry Transformation Systems. Management Science 46(8) 1085-1099.

Deshpande, V., M. Arikan. 2012. The Impact of Airline Flight Schedules on Flight Delays. Manufacturing \& Service Operations Management 14(3): 423-440.

Dertouzos, M. L., R. Lester, R. Solow, F. Dalle. 1990. Made in America, InterEditions, Paris.

*Devaraj, S., K.F. Matta, E. Conlon. 2001. Product and Service Quality: The Antecedents of Customer Loyalty in the Automotive Industry. Production and Operations Management 10(4) 424-439.

\#Dey, A., K.K. Sinha, S. Thirumalai. 2013. It Capability for Health Care Delivery: Is More Better? Journal of Service Research 16(3) 326-340.

\#Dholakia, U.M., S.S. Singh, R.A. Westbrook. 2010. Understanding the Effects of Post-Service Experience Surveys on Delay and Acceleration of Customer Purchasing Behavior: Evidence from the Automotive Services Industry. Journal of Service Research 13(4) 362-378.

*Dostaler, I. 2001. Beyond Practices: A Qualitative Inquiry into High Performance Electronics Assembly. Production and Operations Management 10(4) 478-493.

Edmondson, A. C., S. E. McManus. 2007. Methodological Fit in Management Field Research. Academy of Management Review 32(4) 1155-1179.

Erzurumlu, S. S., J. Davies, N. Joglekar. 2014. Managing Highly Innovative Projects: The Influence of Design Characteristics on Project Valuation. IEEE Transactions on Engineering Management 61(2) 349361. 
\#Feng, Q., L.X. Lu. 2012. The Strategic Perils of Low Cost Outsourcing. Management Science 58(6) 11961210.

\#Ferdows, K., A. De Meyer. 1990. Lasting Improvements in Manufacturing Performance: In Search of a New Theory. Journal of Operations Management 9(2) 168-184.

\#Fernandez-Mateo, I., Z. King. 2011. Anticipatory Sorting and Gender Segregation in Temporary Employment. Management Science 57(6) 989-1008.

\#Fifarek, B.J., F.M. Veloso, C.I. Davidson. 2008. Offshoring Technology Innovation: A Case Study of Rare-Earth Technology. Journal of Operations Management 26(2) 222-238.

Fine, C. H. 1998. Clockspeed: Winning Industry Control in the Age of Temporary Advantage. Basic Books, New York.

Fisher, M. 2007. Strengthening the Empirical Base of Operations Management. Manufacturing \& Service Operations Management 9(4) 368-382.

Fisher, M. 2013. Foreword: Special Issue on Retail Operations. Production and Operations Management 22(4) 755-757.

\#Fisher, M., K. Ramdas, K. Ulrich. 1999. Component Sharing in the Management of Product Variety: A Study of Automotive Braking Systems. Management Science 45(3) 297-315.

\#Fixson, S. K., Y. Ro, J. K. Liker. 2005. Modularisation and Outsourcing: Who Drives Whom? A Study of Generational Sequences in the US Automotive Cockpit Industry. International Journal of Automotive Technology and Management 5(2) 166-183.

Fransman, M. 2010. The New ICT Ecosystem: Implications for Policy and Regulation, Cambridge University Press, Cambridge, UK.

*Fransoo, J.C., C.-Y. Lee. 2013. The Critical Role of Ocean Container Transport in Global Supply Chain Performance. Production and Operations Management 22(2) 253-268.

\#French, M.L., R.L. LaForge. 2006. Closed-Loop Supply Chains in Process Industries: An Empirical Study of Producer Re-Use Issues. Journal of Operations Management 24(3) 271-286.

Fuchs, E. R. 2014. Global Manufacturing and the Future of Technology. Science 345(6196) 519-520.

\#Fuchs, E., R. Kirchain. 2010. Design for Location? The Impact of Manufacturing Offshore on Technology Competitiveness in the Optoelectronics Industry. Management Science 56(12) 2323-2349.

*Fung, M.K. 2008. To What Extent Are Labor-Saving Technologies Improving Efficiency in the Use of Human Resources? Evidence from the Banking Industry. Production and Operations Management 17(1) 75-92.

*Gaimon, C., A. Morton. 2005. Investment in Facility Changeover Flexibility for Early Entry into HighTech Markets. Production and Operations Management 14(2) 159-174.

\#Gao, G., A. Gopal, R. Agarwal. 2010. Contingent Effects of Quality Signaling: Evidence from the Indian Offshore It Services Industry. Management Science 56(6) 1012-1029.

*Gaur, V., M.L. Fisher. 2005. In-Store Experiments to Determine the Impact of Price on Sales. Production and Operations Management 14(4) 377-387. 
Gaur, V., M. L. Fisher, A. Raman. 2005. An Econometric Analysis of Inventory Turnover Performance in Retail Services. Management Science 51(2) 181-194.

Giarratani, F., G. J. Hewings, P. McCann. 2013. Handbook of Industry Studies and Economic Geography, Edward Elgar Publishing, Northampton, MA, USA.

*Giloni, A.V.I., S. Seshadri, P.V. Kamesam. 2003. Service System Design for the Property and Casualty Insurance Industry. Production and Operations Management 12(1) 62-78.

\#Girotra, K., C. Terwiesch, K.T. Ulrich. 2007. Valuing R\&D Projects in a Portfolio: Evidence from the Pharmaceutical Industry. Management Science 53(9) 1452-1466.

Gittell, J. H. 2003. The Southwest Airlines Way: Using the Power of Relationships to Achieve High Performance. McGraw-Hill New York.

Gomory, R. 1993. Testimony before the Senate Armed Services Committee, Subcommittee on Defence Technology, Acquisition, and Industrial Base, June 8, 1993.

\#Gopal, A., G. Gao. 2009. Certification in the Indian Offshore It Services Industry. Manufacturing \& Service Operations Management 11(3) 471-492.

\#Gopal, A., M. Goyal, S. Netessine, M. Reindorp. 2013. The Impact of New Product Introduction on Plant Productivity in the North American Automotive Industry. Management Science 59(10) 2217-2236.

*Grahovac, J., G. Parker, E. Shittu. 2015. The Impact of Costliness, Competitive Importance, and Modularity of Investments on Outsourcing. Production and Operations Management 24(3) 421-437.

*Gralla, E., J. Goentzel, C. Fine. 2014. Assessing Trade-Offs among Multiple Objectives for Humanitarian Aid Delivery Using Expert Preferences. Production and Operations Management 23(6) 978-989.

\#Gray, J.V., A.V. Roth, M.J. Leiblein. 2011. Quality Risk in Offshore Manufacturing: Evidence from the Pharmaceutical Industry. Journal of Operations Management 29(7-8) 737-752.

*Gray, J.V., B. Massimino. 2014. The Effect of Language Differences and National Culture on Operational Process Compliance. Production and Operations Management 23(6) 1042-1056.

*Gray, J.V., B. Tomlin, A.V. Roth. 2009. Outsourcing to a Powerful Contract Manufacturer: The Effect of Learning-by-Doing. Production and Operations Management 18(5) 487-505.

Gray, J.V., A.V. Roth, B. Tomlin. 2014. Quality Risk and Contract Manufacturing: Theory and Empirical Evidence. The Ohio State University Working Paper, Columbus, $\mathrm{OH}$.

Grindley, P., D. C. Mowery, B. Silverman. 1994. Sematech and Collaborative Research: Lessons in the Design of High-Technology Consortia. Journal of policy analysis and management 13(4) 723-758.

*Guo, H., H.K. Cheng, S. Bandyopadhyay. 2013. Broadband Network Management and the Net Neutrality Debate. Production and Operations Management 22(5) 1287-1298. Hammer, M. 2004. Deep Change: How Operational Innovation can Transform Your Company. Harvard Business Review 82(4) 84-93.

*Handley, S.M., J.V. Gray. 2013. Inter-Organizational Quality Management: The Use of Contractual Incentives and Monitoring Mechanisms with Outsourced Manufacturing. Production and Operations Management 22(6) 1540-1556.

\#Hatch, N.W., D.C. Mowery. 1998. Process Innovation and Learning by Doing in Semiconductor Manufacturing. Management Science 44(11) 1461-1477. 
*Hatzakis, E.D., S.K. Nair, M. Pinedo. 2010. Operations in Financial Services-an Overview. Production and Operations Management 19(6) 633-664.

Hausman, J. A. and W. E. Taylor. 1981. Panel Data and Unobservable Individual Effects. Econometrica 49(6) 1377-1398.

*Hausman, W.H., H.L. Lee, U. Subramanian. 2013. The Impact of Logistics Performance on Trade. Production and Operations Management 22(2) 236-252.

Hayes, R. H. and G. P. Pisano. 1996. Manufacturing Strategy: At the Intersection of Two Paradigm Shifts. Production and Operations Management 5(1) 25-41.

\#Heim, G.R., K.K. Sinha. 2001. Operational Drivers of Customer Loyalty in Electronic Retailing: An Empirical Analysis of Electronic Food Retailers. Manufacturing \& Service Operations Management 3(3) 264-271.

*Heim, G.R., K.K. Sinha. 2002. Service Process Configurations in Electronic Retailing: A Taxonomic Analysis of Electronic Food Retailers. Production and Operations Management 11(1) 54-74.

*Helm, J.E., S. AhmadBeygi, M.P. Van Oyen. 2011. Design and Analysis of Hospital Admission Control for Operational Effectiveness. Production and Operations Management 20(3) 359-374.

Helper, S. 2000. Economists and field research: You can observe a lot just by watching. American Economic Review 90(2) 228-232.

Helper, S. 2015. Industry Studies: How It Can Improve Public Policy? Presentation at the Annual Industry Studies Association Conference, Kansas City, MO.

\#Hendricks, K.B., V.R. Singhal. 1997. Does Implementing an Effective TQM Program Actually Improve Operating Performance? Empirical Evidence from Firms That Have Won Quality Awards. Management Science 43(9) 1258-1274.

*Hendricks, K.B., V.R. Singhal. 2005. An Empirical Analysis of the Effect of Supply Chain Disruptions on Long-Run Stock Price Performance and Equity Risk of the Firm. Production and Operations Management 14(1) 35-52.

\#Henisz, W.J., J.T. Macher. 2004. Firm- and Country-Level Trade-Offs and Contingencies in the Evaluation of Foreign Investment: The Semiconductor Industry, 1994-2002. Organization Science 15(5) 537-554.

\#Hill, C.A., G.D. Scudder. 2002. The Use of Electronic Data Interchange for Supply Chain Coordination in the Food Industry. Journal of Operations Management 20(4) 375-387.

Holweg, M. 2007. The Genealogy of Lean Production. Journal of Operations Management 25(2) 420-437.

Holsti, O.R. 1969. Content Analysis for the Social Sciences and Humanities. Addison-Wesley Publishing Company Inc, Reading, MA.

\#Holweg, M., S.M. Disney, P. Hines, M.M. Naim. 2005. Towards Responsive Vehicle Supply: A Simulation-Based Investigation into Automotive Scheduling Systems. Journal of Operations Management 23(5) 507-530.

*Hora, M., D.K. Dutta. 2013. Entrepreneurial Firms and Downstream Alliance Partnerships: Impact of Portfolio Depth and Scope on Technology Innovation and Commercialization Success. Production and Operations Management 22(6) 1389-1400. 
Hsiao, C. 2014. Analysis of Panel Data, Cambridge University Press. Cambridge, UK.

*Hu, Q., L.B. Schwarz. 2011. Controversial Role of GPOs in Healthcare-Product Supply Chains. Production and Operations Management 20(1) 1-15.

Huckman, R. S. and D. E. Zinner. 2008. Does Focus Improve Operational Performance? Lessons from the Management of Clinical Trials. Strategic Management Journal 29(2) 173-193.

\#Hyer, N.L., U. Wemmerlöv, J.A. Morris Jr. 2009. Performance Analysis of a Focused Hospital Unit: The Case of an Integrated Trauma Center. Journal of Operations Management 27(3) 203-219.

ISA, 2015. Industry Studies Association. Available at www.industrystudies.org/awards (accessed date September 9, 2015).

*Iyer, A., H. Saranga, S. Seshadri. 2013. Effect of Quality Management Systems and Total Quality Management on Productivity before and After: Empirical Evidence from the Indian Auto Component Industry. Production and Operations Management 22(2) 283-301.

*Jack, E.P., A.S. Raturi. 2003. Measuring and Comparing Volume Flexibility in the Capital Goods Industry. Production and Operations Management 12(4) 480-501.

*Jack, E.P., T.L. Powers. 2004. Volume Flexible Strategies in Health Services: A Research Framework. Production and Operations Management 13(3) 230-244.

\#Jambulingam, T., R. Kathuria, W.R. Doucette. 2005. Entrepreneurial Orientation as a Basis for Classification within a Service Industry: The Case of Retail Pharmacy Industry. Journal of Operations Management 23(1) 23-42.

Januszewski, S. 2003. Essays on the Industrial Organization of the Airline Industry, Unpublished Ph. D Thesis, Massachusetts Institute of Technology.

\#Kapoor, R., T. Klueter. 2015. Decoding the Adaptability-Rigidity Puzzle: Evidence from Pharmaceutical Incumbents' Pursuit of Gene Therapy and Monoclonal Antibodies. Academy of Management Journal 58(4) 1180-1207.

Katok, E., T. Olsen,V. Pavlov. 2012. Wholesale Pricing under Mild and Privately Known Concerns for Fairness. Production and Operations Management 23(2) 285-302

Katzenstein, W., J. Apt. 2012. The Cost of Wind Power Variability. Energy Policy 51: 233-243.

KC, D. S., C. Terwiesch. 2009. Impact of Workload on Service Time and Patient Safety: An Econometric Analysis of Hospital Operations. Management Science 55(9) 1486-1498.

\#KC, D.S., C. Terwiesch. 2011. The Effects of Focus on Performance: Evidence from California Hospitals. Management Science 57(11) 1897-1912.

\#Kesavan, S., V. Gaur, A. Raman. 2010. Do Inventory and Gross Margin Data Improve Sales Forecasts for U.S. Public Retailers? Management Science 56(9) 1519-1533.

*Ketzenberg, M., M.E. Ferguson. 2008. Managing Slow-Moving Perishables in the Grocery Industry. Production and Operations Management 17(5) 513-521.

Kim, S., M. Olivares, G. Weintraub. 2014. Measuring the Performance of Large-Scale Combinatorial Auctions: A Structural Estimation Approach. Management Science 60(5) 1180-1201. 
*King, A.A., M.J. Lenox. 2001. Lean and Green? An Empirical Examination of the Relationship between Lean Production and Environmental Performance. Production and Operations Management 10(3) 244-256.

\#Klepper, S. 2007. Disagreements, Spinoffs, and the Evolution of Detroit as the Capital of the U.S. Automobile Industry. Management Science 53(4) 616-631.

Klochikhin, E., J. Lane. 2015. Why Industry Studies? Presentation at the Annual Conference of the Industry Studies Association, Kansas City, Mo.

Kocher, R. P. and E. Y. Adashi. 2011. Hospital Readmissions and the Affordable Care Act: Paying for Coordinated Quality Care. Journal of the American Medical Association 306(16) 1794-1795.

*Kraiselburd, S., P. Yadav. 2013. Supply Chains and Global Health: An Imperative for Bringing Operations Management Scholarship into Action. Production and Operations Management 22(2) 377-381.

*Krass, D., T. Nedorezov, A. Ovchinnikov. 2013. Environmental Taxes and the Choice of Green Technology. Production and Operations Management 22(5) 1035-1055.

*Kretschmer, A., S. Spinler, L.N. Van Wassenhove. 2014. A School Feeding Supply Chain Framework: Critical Factors for Sustainable Program Design. Production and Operations Management 23(6) 990-1001.

Kulkarni, S., U. Apte, N. Evangelopos .2014. The Use of Latent Semantic Analysis in Operations Management Research. Decision Sciences 45(5) 971-994.

\#Kumar, A., R. Telang. 2011. Product Customization and Customer Service Costs: An Empirical Analysis. Manufacturing \& Service Operations Management 13(3) 347-360.

*LaGanga, L.R., S.R. Lawrence. 2012. Appointment Overbooking in Health Care Clinics to Improve Patient Service and Clinic Performance. Production and Operations Management 21(5) 874-888.

Landsbergen, D. and J. F. Orosz. 1996. Why Public Managers Should Not Be Afraid to Enter the" Gray Zone" Strategic Management and Public Law. Administration \& Society 28(2) 238-265.

\#Lane, D.C., C. Monefeldt, J.V. Rosenhead. 2000. Looking in the Wrong Place for Healthcare Improvements: A System Dynamics Study of an Accident and Emergency Department. The Journal of the Operational Research Society 51(5) 518-531.

Lapré, M. A. and N. Tsikriktsis. 2006. Organizational Learning Curves for Customer Dissatisfaction: Heterogeneity across Airlines. Management Science 52(3) 352-366.

*Lapré, M.A. 2011. Reducing Customer Dissatisfaction: How Important Is Learning to Reduce Service Failure? Production and Operations Management 20(4) 491-507.

*Lapré, M.A., G.D. Scudder. 2004. Performance Improvement Paths in the U.S. Airline Industry: Linking Trade-Offs to Asset Frontiers. Production and Operations Management 13(2) 123-134.

Laureiro-Martinez, D., S. Brusoni,N. Canessa, M. Zollo. 2015. Understanding the Exploration-Exploitation Dilemma: An Fmri Study of Attention Control and Decision-Making Performance. Strategic Management Journal 36 (3) 319-338.

Lenway, S. A., K. Rehbein. 1991. Leaders, Followers, and Free Riders: An Empirical Test of Variation in Corporate Political Involvement. Academy of Management Journal 34(4) 893-905.

Lerner, J. 2011. The Future of Private Equity. European Financial Management 17(3): 423-435. 
*Lester, R.K. 1995. Industry Studies and American Industrial Performance. Production and Operations Management 4(3) 187-194.

Lévesque, M., N. Joglekar, J. Davies. 2012. A Comparison of Revenue Growth at Recent-IPO and Established Firms: The Influence of SG\&A, R\&D and COGS. Journal of Business Venturing 27(1) 47-61.

\#Li, J., N. Granados, S. Netessine. 2014. Are Consumers Strategic? Empirical Evidence from the Air Travel Industry. Management Science 60(9) 2114-213.

\#Li, X., B. Gu, H. Liu. 2013. Price Dispersion and Loss-Leader Pricing: Evidence from the Online Book Industry. Management Science 59(6) 1290-1308.

\#Li, Y., B. Cheang, A. Lim. 2012. Grocery Perishables Management. Production and Operations Management 21(3) 504-517.

Lieberman, M.B. 1984. The Learning Curve and Pricing in the Chemical Processing Industries. The RAND Journal of Economics 15(2) 213-228.

\#Lieberman, M. B. 1989. The Learning Curve, Technology Barriers to Entry, and Competitive Survival in the Chemical Processing Industries. Strategic Management Journal 10(5) 431-447.

\#Lieberman, M.B., L. Demeester. 1999. Inventory Reduction and Productivity Growth: Linkages in the Japanese Automotive Industry. Management Science 45(4) 466-485.

Lieberman, M. B., S.Helper, L. Demeester. 1999. The empirical determinants of inventory levels in highvolume manufacturing. Production and Operations Management 8(1) 44-55.

\#Lieberman, M.B., R. Dhawan. 2005. Assessing the Resource Base of Japanese and U.S. Auto Producers: A Stochastic Frontier Production Function Approach. Management Science 51(7) 1060-1075.

Loch, C. H., S. Chick, A. Huchzermeier. 2008. Management Quality and Competitiveness. Springer, Heidelberg, Germany.

\#Lorentz, H., P. Kittipanyangam, J. Singh Srai. 2013. Emerging Market Characteristics and Supply Network Adjustments in Internationalising Food Supply Chains. International Journal of Production Economics 145(1) 220-232.

Lucas, R. E. 1976. Econometric Policy Evaluation: A Critique. Carnegie-Rochester conference series on public policy. Elsevier.

Macher, J. T., D. C. Mowery, T. S. Simcoe. 2002. E-Business and Disintegration of the Semiconductor Industry Value Chain. Industry and Innovation 9(3) 155-181.

\#Macher, J.T. 2006. Technological Development and the Boundaries of the Firm: A Knowledge-Based Examination in Semiconductor Manufacturing. Management Science 52(6) 826-843.

\#Macher, J.T., C. Boerner. 2012. Technological Development at the Boundaries of the Firm: A KnowledgeBased Examination in Drug Development. Strategic Management Journal 33(9) 1016-1036.

\#Macher, J.T., J.W. Mayo, M. Schiffer. 2011. The Influence of Firms on Government. The BE Journal of Economic Analysis \& Policy 11(1).

*Mallick, D.N., R.G. Schroeder. 2005. An Integrated Framework for Measuring Product Development Performance in High Technology Industries. Production and Operations Management 14(2) 142-158.

Mcfadden, D. 1986. The Choice Theory Approach to Market Research. Marketing science 5(4) 275-297. 
Mcgahan, A. M., M. E. Porter. 1997. How Much Does Industry Matter, Really? Strategic Management Journal 18(1) 15-30.

Mcgahan, A. M., R. Victer. 2009. How Much Does Home Country Matter to Corporate Profitability. $J$ International Business Studies 41(1) 142-165.

*Meester, G.A., A. Mehrotra, H.P. Natarajan, M.J. Seifert. 2010. Optimal Configuration of a Service Delivery Network: An Application to a Financial Services Provider. Production and Operations Management 19(6) 725-741.

\#Mendelson, H., R.R. Pillai. 1999. Industry Clockspeed: Measurement and Operational Implications. Manufacturing \& Service Operations Management 1(1) 1-20.

*Menor, L.J., A.V. Roth. 2008. New Service Development Competence and Performance: An Empirical Investigation in Retail Banking. Production and Operations Management 17(3) 267-284.

Miller, J. G., A. V. Roth. 1994. A Taxonomy of Manufacturing Strategies. Management Science 40(3) 285304.

*Narayanan, S., S. Balasubramanian, J.M. Swaminathan. 2011. Managing Outsourced Software Projects: An Analysis of Project Performance and Customer Satisfaction. Production and Operations Management 20(4) 508-521.

\#Neely, A., J. Mills, K. Platts, M. Gregory, H. Richards. 1994. Realizing Strategy through Measurement. International Journal of Operations \& Production Management 14(3) 140-152.

\#Nembhard, I.M., A.L. Tucker. 2011. Deliberate Learning to Improve Performance in Dynamic Service Settings: Evidence from Hospital Intensive Care Units. Organization Science 22(4) 907-922.

Nightingale, D. J., J. H. Mize. 2002. Development of a Lean Enterprise Transformation Maturity Model. Information, Knowledge, Systems Management 3(1) 15-30.

\#Novak, S., S. Stern. 2008. How Does Outsourcing Affect Performance Dynamics? Evidence from the Automobile Industry. Management Science 54(12) 1963-1979.

\#Novak, S., S.D. Eppinger. 2001. Sourcing by Design: Product Complexity and the Supply Chain. Management Science 47(1) 189-204.

\#Oliva, R., J.D. Sterman. 2001. Cutting Corners and Working Overtime: Quality Erosion in the Service Industry. Management Science 47(7) 894-914.

\#Olivares, M., C. Terwiesch, L. Cassorla. 2008. Structural Estimation of the Newsvendor Model: An Application to Reserving Operating Room Time. Management Science 54(1) 41-55.

Olivares, M., G. Cachon. 2009. Competing Retailers and Inventory: An Empirical Investigation of General Motors' Dealerships in Isolated U.S. Markets. Management Science 55(9)1586-1604.

\#Olivares, M., G.Y. Weintraub, R. Epstein, D. Yung. 2012. Combinatorial Auctions for Procurement: An Empirical Study of the Chilean School Meals Auction. Management Science 58(8) 1458-1481.

Ostrom, E. 2000. Collective Action and the Evolution of Social Norms. Journal of Natural Resources Policy Research 6(4) 235-252Parker, G., M. Van Alstyne. 2010. Innovation, Openness \& Platform Control. Proceedings of the 11th ACM conference on Electronic commerce, ACM.

*Parker, G.G., E.G. Anderson. 2002. From Buyer to Integrator: The Transformation of the Supply-Chain Manager in the Vertically Disintegrating Firm. Production and Operations Management 11(1) 75-91. 
*Patrick, J. 2011. Access to Long-Term Care: The True Cause of Hospital Congestion? Production and Operations Management 20(3) 347-358.

\#Peng, C., F. Erhun, E.F. Hertzler, K.G. Kempf. 2012. Capacity Planning in the Semiconductor Industry: Dual-Mode Procurement with Options. Manufacturing \& Service Operations Management 14(2) 170-185.

Peters, T. J., R. H. Waterman. 1982. In Search of Excellence. New York.

\#Pil, F.K., J.P. Macduffie. 1996. The Adoption of High-Involvement Work Practices. Industrial Relations: A Journal of Economy and Society 35(3) 423-455.

Piore, M. J., C. F. Sabel. 1984. The Second Industrial Divide: Possibilities for Prosperity. New York: Basic Books.

Pisano, G. P., R. M. Bohmer, A. C. Edmondson. 2001. Organizational Differences in Rates of Learning: Evidence from the Adoption of Minimally Invasive Cardiac Surgery. Management Science 47(6) 752-768.

Porter, M., C. van der Linde. 1995. Towards a new conception of the environment-competitiveness relationship. Journal of Economic Perspectives 9(4) 97-118.

*Quariguasi-Frota-Neto, J., J. Bloemhof. 2012. An Analysis of the Eco-Efficiency of Remanufactured Personal Computers and Mobile Phones. Production and Operations Management 21(1) 101-114.

\#Rajaram, K., U.S. Karmarkar. 2004. Campaign Planning and Scheduling for Multiproduct Batch Operations with Applications to the Food-Processing Industry. Manufacturing \& Service Operations Management 6(3) 253-269.

\#Ramdas, K., J. Williams, M. Lipson. 2013. Can Financial Markets Inform Operational Improvement Efforts? Evidence from the Airline Industry. Manufacturing \& Service Operations Management 15(3) 405422.

\#Ramdas, K., T. Randall. 2008. Does Component Sharing Help or Hurt Reliability? An Empirical Study in the Automotive Industry. Management Science 54(5) 922-938.

\#Randall, T., K. Ulrich. 2001. Product Variety, Supply Chain Structure, and Firm Performance: Analysis of the U.S. Bicycle Industry. Management Science 47(12) 1588-1604.

*Reiner, G., C. Teller, H. Kotzab. 2013. Analyzing the Efficient Execution of in-Store Logistics Processes in Grocery Retailing - the Case of Dairy Products. Production and Operations Management 22(4) 924939.

Reiss, P. C., F. A. Wolak. 2007. Structural Econometric Modeling: Rationales and Examples from Industrial Organization. Handbook of Econometrics 6: 4277-4415.

Roberts, J. A., I. H. Hann, S. A. Slaughter. 2006. Understanding the motivations, participation, and performance of open source software developers: A longitudinal study of the Apache projects. Management Science 52(7) 984-999.

Rosenzweig, E. D., G. S. Easton. 2010. Tradeoffs in Manufacturing? A Meta-Analysis and Critique of the Literature. Production and Operations Management 19(2) 127-141.

*Rosenzweig, E.D., A.V. Roth. 2004. Towards a Theory of Competitive Progression: Evidence from HighTech Manufacturing. Production and Operations Management 13(4) 354-368.

Roth, A. V. 1996. Competitive progression theory: explanation and evidence. In Manufacturing Strategy, 3rd International Conference of the EurOMA, London 563-568. 
Roth, A.V., R.G. Schroeder, X. Huang, M. Kristal. 2008. Handbook of Metrics for Research in Operations Management. Sage, Thousand Oaks, CA.

\#Roth, A.V., W.E. Jackson. 1995. Strategic Determinants of Service Quality and Performance: Evidence from the Banking Industry. Management Science 41(11) 1720-1733.

Rungtusanatham, M.J., J.W. Miller, K.K. Boyer. 2014. Theorizing, Testing, and Concluding for Mediation in SCM Research: What to Do, What Not to Do. Journal of Operations Management. 32(3) 99-113.

Rungtusanatham, M.J., F. Salvador. 2008. From Mass Production to Mass Customization: Hindrance Factors, Structural Inertia, and Transition Hazard. Production and Operations Management 17(3) 385-396.

Rungtusanatham, M.J., T. Y. Choi, D. G. Hollingworth, Z. Wu, C. Forza. 2003. Survey Research in Operations Management: Historical Analyses. Journal of Operations Management 21(4) 475-488.

Sako, M., S. Helper (1998). Determinants of trust in supplier relations: Evidence from the automotive industry in Japan and the United States. Journal of Economic Behavior \& Organization 34(3) 387-417.

\#Salomon, R., X. Martin. 2008. Learning, Knowledge Transfer, and Technology Implementation Performance: A Study of Time-to-Build in the Global Semiconductor Industry. Management Science 54(7) 1266-1280.

*Salzarulo, P.A., K.M. Bretthauer, M.J. Côté, K.L. Schultz. 2011. The Impact of Variability and Patient Information on Health Care System Performance. Production and Operations Management 20(6) 848-859.

Schmalensee, R. 1989. Inter-Industry Studies of Structure and Performance. Handbook of industrial organization 2: 951-1009.

Schmenner, R. W., M. L. Swink. 1998. On Theory in Operations Management. Journal of Operations Management 17(1) 97-113.

*Schmenner, R.W. 2001. History of Technology, Manufacturing, and the Industrial Revolution: A Rejoinder. Production and Operations Management 10(1) 103-106.

Schoenherr, T., D. Power, R. Narasimhan, D. Samson 2012. Competitive Capabilities among Manufacturing Plants in Developing, Emerging, and Industrialized Countries: A Comparative Analysis. Decision Sciences 43(1) 37-72.

Senge, P. M., J. D. Sterman. 1992. Systems Thinking and Organizational Learning: Acting Locally and Thinking Globally in the Organization of the Future. European journal of operational research 59(1) 137150.

Senge, P. M., J. Suzuki. 1994. The Fifth Discipline: The Art and Practice of the Learning Organization. Currency Doubleday New York.

Shah, R., P. T. Ward. 2007. Defining and Developing Measures of Lean Production. Journal of Operations Management 25(4) 785-805.

\#Shah, R., P.T. Ward. 2003. Lean Manufacturing: Context, Practice Bundles, and Performance. Journal of Operations Management 21(2) 129-149.

\#Shah, R., S.M. Goldstein, B.T. Unger, T.D. Henry. 2008. Explaining Anomalous High Performance in a Health Care Supply Chain. Decision Sciences 39(4) 759-789.

Sims, C. A. 1972. Money, income, and causality. The American Economic Review 62(4) 540-552. 
*Singhal, K. 2001. History of Technology, Manufacturing, and the Industrial Revolution: An Alternate Perspective on Schmenner's Hypotheses. Production and Operations Management 10(1) 97-102.

*Skinner, W. 1996. Three Yards and a Cloud of Dust: Industrial Management at Century End. Production and Operations Management 5(1) 15-24.

\#Sodhi, M.S., C.S. Tang. 2013. Strategies and Tactics of Chinese Contract Manufacturers and Western Oems (2001-2011). International Journal of Production Economics 146(1) 14-24.

*Sodhi, M.S., C.S. Tang. 2014. Buttressing Supply Chains against Floods in Asia for Humanitarian Relief and Economic Recovery. Production and Operations Management 23(6) 938-950.

*Somlo, B., K. Rajaram, R. Ahmadi. 2011. Distribution Planning to Optimize Profits in the Motion Picture Industry. Production and Operations Management 20(4) 618-636.

\#Srai, J.S., M. Gregory. 2008. A Supply Network Configuration Perspective on International Supply Chain Development. International Journal of Operations \& Production Management 28(5) 386-411.

\#Stan, M., F. Vermeulen. 2013. Selection at the Gate: Difficult Cases, Spillovers, and Organizational Learning. Organization Science 24(3) 796-812.

\#Stank, T.P., T.J. Goldsby, S.K. Vickery. 1999. Effect of Service Supplier Performance on Satisfaction and Loyalty of Store Managers in the Fast Food Industry. Journal of Operations Management 17(4) 429-447.

Sterman, J.D. 2000. Business Dynamics: Systems Thinking and Modeling for a Complex World. Irwin/McGraw-Hill, Boston.

Stratman, J. K. 2007. Realizing Benefits from Enterprise Resource Planning: Does Strategic Focus Matter? Production and Operations Management 16(2) 203-216.

\#Suarez, F.F., M.A. Cusumano, S.J. Kahl. 2013. Services and the Business Models of Product Firms: An Empirical Analysis of the Software Industry. Management Science 59(2) 420-435.

Swank, C. K. (2003). The lean service machine. Harvard Business Review 81(100) 123-130.

*Tatikonda, M.V., S.A. Terjesen, P.C. Patel, V. Parida. 2013. The Role of Operational Capabilities in Enhancing New Venture Survival: A Longitudinal Study. Production and Operations Management 22(6) 1401-1415.

*Tatsiopoulos, I.P., S.T. Ponis, E.A. Hadzilias, N.A. Panayiotou. 2002. Realization of the Virtual Enterprise Paradigm in the Clothing Industry through E-Business Technology. Production and Operations Management 11(4) 516-530.

Teece, D. J. 2007. Explicating Dynamic Capabilities: The Nature and Microfoundations of (Sustainable) Enterprise Performance. Strategic Management Journal 28(13) 1319-1350.

*Theokary, C., Z. Justin Ren. 2011. An Empirical Study of the Relations between Hospital Volume, Teaching Status, and Service Quality. Production and Operations Management 20(3) 303-318.

\#Thirumalai, S., K.K. Sinha. 2011. Product Recalls in the Medical Device Industry: An Empirical Exploration of the Sources and Financial Consequences. Management Science 57(2) 376-392.

Thompson, D. N., G. A. Wolf, S. J. Spear. 2003. Driving Improvement in Patient Care: Lessons from Toyota. Journal of Nursing Administration 33(11) 585-595. 
*Toyasaki, F., T. Boyacı, V. Verter. 2011. An Analysis of Monopolistic and Competitive Take-Back Schemes for WEEE Recycling. Production and Operations Management 20(6) 805-823.

\#Tsikriktsis, N. 2007. The Effect of Operational Performance and Focus on Profitability: A Longitudinal Study of the U.S. Airline Industry. Manufacturing \& Service Operations Management 9(4) 506-517.

\#Tsikriktsis, N., J. Heineke. 2004. The Impact of Process Variation on Customer Dissatisfaction: Evidence from the U.S. Domestic Airline Industry. Decision Sciences 35(1) 129-141.

\#Tucker, A.L. 2007. An Empirical Study of System Improvement by Frontline Employees in Hospital Units. Manufacturing \& Service Operations Management 9(4) 492-505.

*Tucker, A.L., S.J. Singer. 2015. The Effectiveness of Management-by-Walking-Around: A Randomized Field Study. Production and Operations Management 24(2) 253-271.

\#Vereecke, A., R. Van Dierdonck, A. De Meyer. 2006. A Typology of Plants in Global Manufacturing Networks. Management Science 52(11) 1737-1750.

Van Donselaar, K.H., V. Gaur, T. Van Woensel, R.A.C.M. Broekmeulen, J. Fransoo. 2010. Ordering Behavior in Retail Stores and Implications for Automated Replenishment. Management Science 56(5) 766784.

\#Victorino, L., R. Verma, G. Plaschka, C. Dev. 2005. Service Innovation and Customer Choices in the Hospitality Industry. Managing Service Quality 15(6) 555-576.

*Ward, P.T., P.D. Berger, J.G. Miller, S.R. Rosenthal. 1992. Manufacturing Process Technology and Support Staff Composition: An Empirical View of Industry Evidence. Production and Operations Management 1(1) 5-21.

*White, D.L., C.M. Froehle, K.J. Klassen. 2011. The Effect of Integrated Scheduling and Capacity Policies on Clinical Efficiency. Production and Operations Management 20(3) 442-455.

\#White, R.E., J.N. Pearson, J.R. Wilson. 1999. JIT Manufacturing: A Survey of Implementations in Small and Large U.S. Manufacturers. Management Science 45(1) 1-15.

Wilkinson, A., A. Dainty, A. Neely. 2009. Changing Times and Changing Timescales: The Servitization of Manufacturing. International Journal of Operations \& Production Management 29(5).

Womack, J. P., D. T. Jones, D. Roos. 1990. The Machine That Changed the World: The Story of Lean Production. 1st Harper Perennial Ed. New York.

*Xu, Y., H. Gurnani, R. Desiraju. 2010. Strategic Supply Chain Structure Design for a Proprietary Component Manufacturer. Production and Operations Management 19(4) 371-389.

\#Yee, R.W.Y., A.C.L. Yeung, T.C.E. Cheng. 2008. The Impact of Employee Satisfaction on Quality and Profitability in High-Contact Service Industries. Journal of Operations Management 26(5) 651-668.

*Yeung, A.C.L., T.C.E. Cheng, K.-h. Lai. 2005. An Empirical Model for Managing Quality in the Electronics Industry. Production and Operations Management 14(2) 189-204.

*Zhang, H., G.S. Zaric, T. Huang. 2011. Optimal Design of a Pharmaceutical Price-Volume Agreement under Asymmetric Information about Expected Market Size. Production and Operations Management 20(3) 334-346.

\#Zhang, J.J., N. Joglekar, R. Verma. 2012. Pushing the Frontier of Sustainable Service Operations Management. Journal of Service Management 23(3) 377-399. 